\title{
Nephrology, dialysis and transplantation
}

\author{
K. Farrington ${ }^{1}$ and P. Sweny ${ }^{2}$ \\ ${ }^{1}$ Lister Hospital, Stevenage and ${ }^{2}$ Royal Free Hospital, London, UK
}

Nephrology

\section{Urine microscopy}

Careful phase contrast microscopy of freshly prepared urine sediment is one of the simplest, cheapest and most helpful investigations in nephrology and urology, but it is often omitted or delegated to the routine microbiology laboratories. ${ }^{1}$ It should be the first investigation in all cases of haematuria or suspected glomerular disease. The rapid identification of red cell casts or dysmorphic red cells can point the clinicians in the direction of renal biopsy and away from cystoscopy and arteriography. ${ }^{2}$ Doctors investigating renal patients should have access to a centrifuge and a good quality phase contrast microscope. With phase contrast, damaged or distorted red cells can easily be recognized (dysmorphic red cells). ${ }^{3}$ The extremes of osmolarity experienced with passage along the nephron may be important in producing dysmorphic cells. Dysmorphic cells may have gained entry to the urinary tract via a ruptured glomerular basement membrane in an inflamed glomerulus or through a ruptured tubular basement membrane damaged by interstitial inflammation. The injury sustained during this passage is thought more likely to account for their variable and abnormal morphology. ${ }^{4}$ If all the red cells are of a similar size and shape and well preserved, the haematuria is more likely to have been caused by a lesion below the nephron. Urological workup is then appropriate.

\section{Acute renal failure ( $A R F)$}

Progress in this area has centred on efforts to clarify the pathogenesis of ARF and on the development of a variety of potential treatments most of which remain experimental. In the clinical setting, continous modes of renal replacement therapy have become routinely available for the treatment of ARF in the intensive care unit. In spite of this, the mortality remains high.

Correspondence: P. Sweny, M.A., M.D., F.R.C.P., Department of Nephrology and Transplantation, Royal Free Hospital, Pond Street, London NW3 2QG, UK.

\section{Pathogenesis of ARF}

Changes in renal haemodynamics are a feature of all types of ARF irrespective of precipitating insult. Recent studies have examined the role of endothelium-derived vasoactive factors in these changes.

Endothelin Endothelin is a 21-amino acid peptide. It is the most potent vasoconstrictor yet discovered, being ten times more potent than angiotensin II. It has many other properties including effects on ion transport, eicosanoid synthesis, and renin and atrial natriuretic peptide (ANP) release. The renal vasculature appears particularly susceptible to its vasoconstrictive effect. Renal vascular resistance is increased by an effect on both afferent and efferent arterioles. It also reduces the glomerular ultrafiltration coefficient by inducing mesangial cell contraction. ${ }^{5}$ Thus both renal blood flow and glomerular filtration rate (GFR) are compromised (Table I). Factors known to increase its production rate include hypoxia, shear stress, endotoxin, thrombin, adrenalin, neuropeptide $Y$, and interleukin 1. Many of these factors are thought to be important in the pathogenesis of ischaemic ARF. Endothelin may well have a pathogenic role in this setting. In support of this, circulating levels of endothelin have been found to be elevated in patients with ARF. ${ }^{6}$ Experimentally, monoclonal antibodies to endothelin and specific non-peptide endothelin antagonists have been found to protect against the development of postischaemic renal damage. ${ }^{7,8}$ Anti-endothelin antibodies also protected against endotoxin-induced falls in $G^{2} R^{3}$.

Endothelium-derived relaxing factor (EDRF) Vasodilatation in response to acetylcholine and bradykinin is mediated by a diffusible EDRF, which has subsequently been identified as nitric oxide. Its synthesis is catalysed by nitric oxide synthase from $\mathrm{L}$-arginine, and blocked by the arginine analogue L-NMMA. There are two enzyme systems, one constitutive, and responsible for the physiological production of EDRF, and the 
Table I Effects of endothelin and EDRF on renal haemodynamics

\begin{tabular}{|c|c|c|}
\hline & Endothelin & $E D R F$ \\
\hline Renal blood flow & Decreased & Increased \\
\hline Glomerular filtration rate & Decreased & No change \\
\hline Afferent resistance & Increased & Decreased \\
\hline Efferent resistance & Increased & Decreased \\
\hline $\begin{array}{l}\text { Glomerular ultrafiltration } \\
\text { coefficient }\end{array}$ & Decreased & ?Increased \\
\hline
\end{tabular}

other inducible, and responsible for prolonged EDRF production in some pathological circumstances. In addition to its vasodilator effect, nitric oxide inhibits platelet adhesion and aggregation. In these two actions, nitric oxide and prostacyclin potentiate each other. EDRF also reduces the release of renin and ANP' ${ }^{9}$. Infusion of L-NMMA produces hypertension implying a physiological role for EDRF in the maintenance of normal blood pressure. ${ }^{10}$ Endothelium-derived nitric oxide also exhibits profound effects on glomerular haemodynamics, ${ }^{7}$ L-NMMA inducing increased renal vascular resistance, decreased renal blood flow, with little effect on GFR (Table I). In post-ischaemic ARF, the vascular responses to acetylcholine and bradykinin are blunted, suggesting impaired release of EDRF. ${ }^{11}$ Haemoglobin and myoglobin are both potent inhibitors of EDRF, ${ }^{12,13}$ and this action may be important in the pathogenesis of ARF associated with haemolysis and rhabdomyolysis. On the other hand, endotoxin and cytokines can stimulate the inducible nitric oxide synthase to produce a sustained burst of EDRF, with resulting vasodilatation and resistance to vasoconstrictor agents characteristic of septic shock. Administration of L-NMMA to rats with septic shock produced improvements in blood pressure, renal function, and survival. ${ }^{14}$ There is also some limited clinical experience with the use of L-NMMA in septic shock. ${ }^{15}$

\section{Treatment of ARF}

Experimental Calcium antagonists have a number of potentially beneficial effects on the compromised kidney. These include antagonism of preglomerular vasoconstriction, reduction in cellular calcium uptake in response to cell injury, and a possible action as a free radical scavenger. ${ }^{16}$ Protective effects against the development of ARF have been demonstrated in experimental models of a number of different types of ARF including post-ischaemic ${ }^{17}$ and toxic. ${ }^{18}$ Studies have been extended into the clinical setting, in which protective effects of calcium antagonists have been dem- onstrated in the amelioration of radiocontrast induced renal impairment ${ }^{19}$ and post-transplant ARF. ${ }^{20,21}$

ANP alone, or in combination with dopamine, protects against post-ischaemic ARF. ${ }^{22,23}$ The effect of the drugs in combination appears no greater than the effect of ANP alone,${ }^{24}$ in spite of the prevention, by dopamine, of the hypotensive response to ANP. Loop diuretics produced longterm improvement in renal function after an ischaemic insult, perhaps by reducing the proportion of nephrons obstructed by Tamm-Horsfall protein cylinders. ${ }^{25}$

Most studies of therapy in experimental ARF have concentrated on attempts to modify the haemodynamic processes involved in the initiation of the condition. Agents which stimulate regeneration of damaged tubules may also have therapeutic potential. Epidermal growth factor is one such agent. It is a potent growth promoter to renal tubular cells, and has been found to accelerate recovery in mercuric chloride-induced ARF in rats. $^{26}$

Clinical Therapy in ARF is firmly based on aggressive resuscitation and optimization of haemodynamic parameters, attempts to nullify or reverse the precipitating insults, the appropriate use of loop diuretics and low-dose dopamine, and the early institution of renal replacement therapy should sufficient renal function not be restored by these former measures. Continuous modes of renal replacement have become standard in this situation, especially for patients managed in intensive care units. There is very little controlled information comparing different modes of therapy, but the firm clinical impression is that continuous treatments have considerable advantages over intermittent treatments particularly with respect to the maintenance of haemodynamic stability, the degree and stability of metabolic control and the capacity to provide optimal nutrition. A recent controlled trial has reported a significant benefit of pump-driven haemofiltration (continuous venovenous haemofiltration-CVVH) over spontaneous arteriovenous haemofiltration (CAVH). Mortality in the CVVH group was less than in the CAVH group in spite of a comparable degree of control of uraemia apparently based on serum creatinine levels. Mortality was inversely related to the volume of ultrafiltrate. ${ }^{27}$ It was suggested that differences in 'middle molecule' clearance resulting from the differences in ultrafiltration volume might explain the effect. However, static biochemical parameters often provide a poor assessment of the adequacy of renal replacement treatments (vide infra). 


\section{Glomerulonephritis}

\section{i. Mesangial IgA disease}

Mesangial $\operatorname{IgA}$ disease (Berger's disease) is the commonest cause of recurrent episodes of macroscopic haematuria in young adults, a point worth emphasizing to urologists. It is also the commonest type of glomerulonephritis. Recent research has concentrated on three areas: aetiology, prognosis and therapy.

Aetiology Serum IgAl levels are higher than $\operatorname{IgA} 2$ in patients with mesangial IgA disease. This implies a systemic origin of the IgA rather than mucosal. ${ }^{28} \mathrm{~A}$ variety of autoantibodies of IgA class have been described. Circulating complexes of IgA and fibronectin have been demonstrated. ${ }^{29}$ The fibronectin component may be responsible for mesangial deposition of $\operatorname{IgA}$ rather than true $\operatorname{IgA}$ autoimmunity to glomerular antigens. There are other possibilities. IgA autoantibody to fibronectin may be present. Fibronectin may also bind to whatever antigen binds the $\operatorname{IgA}$. An attractive hypothesis is that micro-organisms or their antigens that present to mucosal surfaces are bound to fibronectin. The resulting immune response produces circulating immune complexes of microbial antigens, fibronectin and IgA. Indeed, complexes such as these made in vitro preferentially deposited in the mesangium of experimental animals. ${ }^{30} \operatorname{IgA}$ reacting with human endothelial cell surface antigen has been demonstrated by ELISA and Western blotting in patients with mesangial IgA disease. ${ }^{31}$ Whether these are true autoantibodies to endothelial cells or represent $\operatorname{IgA}$ binding to fibronectin, is not yet clear. IgA - fibronectin complexes appear to be useful serological markers for mesangial $\operatorname{IgA}$ disease and probably also for Henoch-Schönlein purpura (HSP). ${ }^{32}$ The nature of the immune response may be abnormal with low affinity IgA antibodies being produced with no evidence of increasing affinity with time.

Platelets are thought to be involved in the pathogenesis of mesangial IgA disease, as they can be seen in affected glomeruli on electron microscopy. ${ }^{33}$ They may also be found in the urine deposit. ${ }^{34}$ Evidence of platelet involvement can be deduced from the finding of elevated platelet factor 4 levels in urine. ${ }^{35}$ Urinary platelet factor 4 levels may help to differentiate mesangial IgA disease from thin membrane disease, both of which cause persistent isolated microscopic haematuria. The origin of urinary platelet factor 4 is from glomerular inflammation rather than plasma filtration.

Prognosis Twenty-five to $30 \%$ of patients with mesangial IgA disease deteriorate to end-stage chronic renal failure. If prognosis could be ac- curately gauged from initial biopsy then a policy of biopsying all patients with clinical features compatible with mesangial IgA disease may then be justified. Table II summarizes factors associated with a poor prognosis. Elevated urinary interleukin 6(Il6) (originating from mesangial cells or invading macrophages) appears to correlate with an adverse prognosis. ${ }^{39} \mathrm{C} 4 \mathrm{~A}$ deficiency is associated with severe disease, perhaps by reducing solubilization of deposited complexes. ${ }^{40}$ Low molecular weight proteinuria, probably reflecting more extensive tubulo-interstitial damage, also correlates with a poor prognosis. ${ }^{41,42}$

Treatment There are no large-scale randomized, prospective trials of treatment in mesangial $\operatorname{IgA}$ disease showing that any form of therapy is of benefit. Table III summarizes some of the more recent trials. The correlation between proteinuria and hypertension and poor prognosis argues for the early introduction of an angiotensin converting enzyme (ACE) inhibitor. Combinations of antiplatelet agents, warfarin, steroids and cytotoxic drugs have all been tried with some claims of benefit. ${ }^{50}$

ii. Focal necrotizing and crescentic glomerulonephritis

Excluding cases occurring as part of a multi-system disease, primary focal necrotizing and crescentic glomerulonephritis can be caused by antibodies to glomerular basement membrane $(10-25 \%)$, the deposition of immune-complexes $(10-30 \%)$ or be the so-called 'pauci-immune' type (50-70\%) in

Table II Adverse factors in mesangial IgA disease (see Alambartine et al., 1991) $)^{36}$

\section{Clinical}

Older age at onset

Absence of macroscopic haematuria

Arterial hypertension

Nephrotic syndrome

\section{Histological}

Glomerular sclerosis (Okada et al., 1992) ${ }^{37}$

Tubulointerstitial scarring (Nagy et al., 1987)

Vascular sclerosis

Diffuse crescents

Glomerular necrosis

\section{Laboratory}

Urinary Il6 (Dohi et al., 1991) ${ }^{39}$

C4A deficiency (Wyatt et al., 1991)

HLA B35

High serum IgA

Elevated creatinine (Okada, 1992) ${ }^{37}$

Heavy proteinuria (Okada, 1992) (77 $^{37}$

Low molecular weight proteinuria (Nagy, 1987; Woo, $1991)^{38,41}$ 
Table III Trials of therapy in mesangial IgA disease (see Schena (1989) for review ${ }^{43}$ )

\begin{tabular}{|c|c|c|}
\hline Agent & Author (year) & Outcome \\
\hline Steroids & $\begin{array}{l}\text { Kobayashi }(1987)^{44} \\
\text { Lai }(1987 b)^{45}\end{array}$ & ? Helpful if nephrotic \\
\hline Cyclosporin A & Lai $(1987 a)^{46}$ & Transient decreased proteinuria \\
\hline Eicosapentaenoic acid & Bennet $(1989)^{47}$ & \\
\hline $\begin{array}{l}\text { Cyclophosphamide }+ \\
\text { dipyridamole }+ \text { warfarin }\end{array}$ & Woo $(1991)^{41}$ & $\begin{array}{l}\text { No benefit } \\
\text { Stable renal function }\end{array}$ \\
\hline Dipyridamole + warfarin & $\begin{array}{l}\text { Lee }(1989)^{48} \\
\text { Chan }(1987)^{49}\end{array}$ & $\begin{array}{l}\text { Less proteinuria } \\
\text { Stable renal function }\end{array}$ \\
\hline Phenytoin & Egido $(1984)^{50}$ & $\begin{array}{l}\text { Less proteinuria } \\
\text { No benefit }\end{array}$ \\
\hline
\end{tabular}

which antibodies to neutrophil cytoplasmic antigens antinuclear cytoplasmic antibody (ANCA) are frequently detected. With the exception of anti-glomerular basement membrane antibody-mediated disease, treatment with high dose steroids and cyclophosphamide, at least in the short term, appears effective. In anti-glomerular basement membrane antibody-mediated disease, immediate plasma exchange in addition to drug therapy is considered mandatory to preserve renal function. Plasma exchange as an adjunct to immunosuppressive drugs remains an option in other forms of crescentic nephritis, particularly if severe renal impairment is present. ${ }^{51}$ In one recent study plasma exchange was shown to be of benefit only in dialysis-dependent patients, other patients doing just as well with combination drug therapy. ${ }^{52}$

iii. Glomerulonephritis in human immunodeficiency virus (HIV)-positive patients

Two well-characterized nephropathies have recently been described in HIV-positive patients. ${ }^{53}$ Microalbuminuria may precede overt nephropathy ${ }^{54}$ and appears to be a marker for acquired immunodeficiency syndrome (AIDS) progression being positively correlated with low CD4 counts, lymphopaenia, tumour necrosis factor alpha, and elevated beta-2-microglobulin levels.

HIV-associated nephropathy (HIVAN) The light microscopy appearances of this lesion are of focal and segmental glomerulosclerosis. ${ }^{55}$ This is a rapidly deteriorating severe nephrotic syndrome with progression to chronic renal failure in about 4 months. Blood pressure is usually normal and oedema often minimal. It is seen typically, but not exclusively, in young, black intravenous drug abusers. It is distinct from heroin nephropathy. Nephrotic syndrome can precede AIDS by many months. On ultrasound the kidneys are echogenic and enlarged remaining so despite progression to chronic renal failure. Hyperlipidaemia is said to be less marked than in other types of nephrotic syndrome. Histologically the lesion is similar to focal segmental glomerulosclerosis with deposits of IgM, C3 and Clq. Endothelial cells contain numerous tubulo-reticular inclusion bodies. There are numerous nuclear bodies in the interstitial cells. Microcystic dilatation of the tubules is prominent. Despite these appearances which suggest the presence of viral particles, HIV antigens and DNA have not always been demonstrated in renal tissue. Prognosis is poor with death in 12 months despite dialysis. There is no effective treatment.

IgA nephropathy The light microscopy lesion seen is a mesangial proliferative glomerulonephritis. ${ }^{56}$ Compared with HIVAN this is a relatively benign condition characterized clinically by microscopic haematuria and moderate proteinuria. Idiotypic IgA antibody reacting with anti-HIV IgG or IgM is present in the blood. ${ }^{57}$ Elution studies have shown the presence of HIV DNA in the kidney.

iv. Serological tests for glomerulonephritis and vasculitis

Diagnosis and monitoring The laboratory investigation of patients with glomerulonephritis/vasculitis hopes to provide a specific diagnosis and to measure disease activity so that response to therapy can be monitored. Tables IV and V summarize diagnostic tests that can support a clinical or histological diagnosis in glomerulonephritis. Some of these tests also provide clinically useful markers of disease activity. It is helpful to attempt to define which laboratory parameters best reflect disease activity in an individual patient. Anti-entactin antibodies are found in many types of primary glomerulonephritis (proliferative, crescentic, membranous, membranoproliferative, IgA nephropathy) and therefore have little diagnostic value. ${ }^{59} \mathrm{Of}$ most value are C-reactive protein, $\mathrm{ANCA},{ }^{62}$ antibodies to native double-strand DNA, C3 and C4 and of course creatinine clearance and 24 hour protein. The limited causes of low complement 
Table IV Laboratory markers in primary glomerulonephritis

Primary glomerulonephritis (GN)

\begin{tabular}{|c|c|c|}
\hline $\begin{array}{l}\text { Lesion } \\
\text { (Caucasians) }\end{array}$ & Laboratory marker & HLA associations \\
\hline Minimal change & Highly selective proteinuria & $\begin{array}{l}\text { DR7, B8, B12 } \\
\text { DQW2 }\end{array}$ \\
\hline \multicolumn{3}{|l|}{ Diffuse proliferative } \\
\hline Post-infections & & DR4 \\
\hline Idiopathic & Low C3 (Hebert, 1991) ${ }^{58}$ & \\
\hline $\begin{array}{l}\text { Focal/mesangial proliferative } \\
\text { Idiopathic }\end{array}$ & None & \\
\hline Mesangial $\operatorname{IgA}$ & $\begin{array}{l}\text { None } \\
\text { IgA-fibronectin complexes (Cederholm et al., 1988) }\end{array}$ & BW35, DQW7 \\
\hline Membranous & IgA anti-entactin Ab (Saxena, 1991) ${ }^{59}$ & $\mathrm{~B} 8+\mathrm{DR} 3$ \\
\hline $\begin{array}{l}\text { Focal segmental } \\
\text { glomerulosclerosis }\end{array}$ & $\begin{array}{l}\text { Urinary C5b-9 (Schulze et al., 1991) } \\
\text { None }\end{array}$ & ?DR4, DR3 + 7 \\
\hline $\begin{array}{l}\text { Focal nectrotizing and } \\
\text { crescentic }\end{array}$ & $\begin{array}{l}\text { ANCA (Kallenberg \& Tervaert 1992) } \\
\text { Anti-GBM Ab }\end{array}$ & $\begin{array}{l}\text { DQW7 } \\
\text { B7 + DRW15(DR2) } \\
\quad+\text { DQW6 }\end{array}$ \\
\hline Membranoproliferative & $\begin{array}{l}\text { Low C3 (Hebert, 1991) } \\
\text { C3 Nephritic factor }\end{array}$ & $\begin{array}{l}\text { DR7? } \\
\text { B8 + DR3 }\end{array}$ \\
\hline
\end{tabular}

Table V Diagnosis and monitoring of disease activity in the multi-system vasculitides with GN

\begin{tabular}{|c|c|c|c|c|c|c|c|}
\hline $\begin{array}{l}\text { Disease } \\
\text { Diagnosis }\end{array}$ & $\begin{array}{l}\text { Micro PA } \\
\text { pANCA }\end{array}$ & $\begin{array}{l}\text { SLE } \\
\alpha \text { ds DNA Ab }\end{array}$ & $\begin{array}{l}\text { HSP } \\
\text { IgA } \\
\text { complexes }\end{array}$ & $\begin{array}{l}\text { SBE } \\
+ \text { ve blood } \\
\text { culture } \\
\text { ECHO }\end{array}$ & $\begin{array}{l}\text { WG } \\
\text { cANCA }\end{array}$ & $\begin{array}{l}\text { C-SS } \\
\text { pANCA } \\
\text { CXR } \\
\text { Eosinophilia }\end{array}$ & $\begin{array}{l}\text { Cryog } \\
\text { Cryoglobulins } \\
\text { C4 }\end{array}$ \\
\hline Activity & $\begin{array}{l}\text { pANCA } \\
\text { CRP } \\
\text { PMN count }\end{array}$ & $\begin{array}{l}\alpha \text { ds DNA Ab } \\
\text { C3 } \\
\text { C4 } \\
\text { CRP }\end{array}$ & & $\begin{array}{l}\text { SCAT } \\
\text { CRP } \\
\text { C3 } \\
\text { C4 }\end{array}$ & $\begin{array}{l}\text { cANCA } \\
\text { CRP }\end{array}$ & & $\begin{array}{l}\text { Cryocrit } \\
\text { C4 } \\
\text { SCAT }\end{array}$ \\
\hline
\end{tabular}

$\alpha$ ds DNA $\mathrm{AB}=$ antibody to native double-strand DNA; CRP $=$ C-reactive protein; $\mathrm{PMN}=$ polymorphonuclear leucocyte; $\mathrm{SCAT}=$ sheep red cell agglutination titre; $\mathrm{CXR}=$ chest $\mathrm{X}$-ray; $\mathrm{ECHO}=$ echocardiogram; $\mathrm{Micro} \mathrm{PA}=$ microscopic polyarteritis; SLE = systemic lupus erythematosus; HSP = Henoch Schönlein purpura; SBE = subacute bacterial endocarditis; WG $=$ Wegener's granulomatosis; C-SS $=$ Churg-Strauss syndrome; Cryog $=$ cryoglobulinaemia; pANCA = perinuclear and nuclear anti-neutrophil cytoplasmic antibody (ANCA); $\mathrm{cANCA}=$ diffuse cytoplasmic staining ANCA.

levels are of diagnostic value (Table VI). Repeated urine microscopy (see above) should not be overlooked as a marker of disease activity.

Anti-neutrophil cytoplasmic antibody (ANCA) ANCA is best detected by testing serum on alcoholfixed buffy coat polymorphs. Two patterns of staining are recognized: cANCA (diffuse cytoplasmic staining) and pANCA (perinuclear and nuclear). ${ }^{61}$ The antigens involved have been identified (Table VII). It is now known that the perinuclear and nuclear staining is an artefact caused by alcohol fixation which allows the cationic myeloperoxidase antigen to bind the anionic nuclear membrane (fixation with formalin or glutaraldehyde shows the true pattern of antigen distribution and gives a cytoplasmic pattern). False positive results may therefore be seen in patients with antinuclear antibodies and antibodies to elas- tase or lactoferrin. Confirmation of a pANCA by ELISA with a purified antigen is necessary. ${ }^{61 a}$

Anti-proteinase 3 and anti-myeloperoxidase antibodies can activate primed neutrophils in vitro. These antibodies bind to the site on the enzyme normally occupied by the natural inhibitor of the proteinase. If polymorphonuclear leucocytes are activated by intercurrent infections then antiproteinase antibodies could provoke a flare of the underlying disease. Proteinase 3 is highly cationic and would be expected to bind to anionic sites in the glomerulus. In pauci-immune necrotizing/ crescentic glomerulonephritis a cell-mediated immune response could be responsible for the glomerulitis.

Lupus anticoagulant The kidney in systemic lupus erythematosus (SLE) may be damaged by the deposition of immune complexes (glomeruloneph- 
Table VI Causes of low complement levels (Hebert et al., 1991)

I. Immune mediated

(A) Associated with GN

Post-infections GN C3

Membranoproliferative GN C3

Subacute bacterial endocarditis $\quad \mathrm{C} 3, \mathrm{C} 4$

Lupus-like syndromes $\quad \mathrm{C} 2$ deficiency, $\mathrm{C} 4$ null allele

Cryoglobulinaemia $\quad$ C3, C4

Systemic lupus erythematosus $\quad$ C3, C4

GN associated with persistent

active infections

(B) Not usually associated with GN

Vasculitis

Rheumatoid $\quad \mathrm{C} 3, \mathrm{C} 4$

Idiopathic C3, C4

Drug-induced lupus $\quad$ C3, C4

Serum sickness $\quad$ C3, C4

Drug hypersensitivity C3, C4

Chemotherapy for lymphoma/leukaemia $\quad \mathrm{C} 3, \mathrm{C} 4$

Thyroiditis C3, C4

B-cell lymphoproliferative disorders $\quad \mathrm{C} 4, \mathrm{C} 2$

II. Non-immune mediated

Atheroembolism C3

Severe sepsis $\quad$ C3, C4

HUS, TTP C3

Acute pancreatitis $\quad \mathrm{C} 3, \mathrm{C} 4$

Malnutrition $\quad \mathrm{C} 3$

Jejunal ileal bypass $\quad \mathrm{C} 3, \mathrm{C} 4$

Severe liver disease $\quad \mathrm{C} 3, \mathrm{C} 4$

Burns $\quad \mathrm{C} 3, \mathrm{C} 4$

Acute myocardial infarction $\quad \mathrm{C} 3, \mathrm{C} 4$

Haemolytic crisis in malaria $\quad \mathrm{C} 3, \mathrm{C} 4$

$\mathrm{GN}=$ glomerulonephritis; HUS = haemolytic-uraemic syndrome; TTP = thrombotic thrombocytopenic purpura.

Table VII Anti-neutrophil cytoplasmic antibodies (ANCA)

\begin{tabular}{|c|c|c|}
\hline & & \\
\hline & $c A N C A$ & $p A N C A$ \\
\hline $\begin{array}{l}\text { Pattern } \\
\text { (ethanol-fixed buffy coat) }\end{array}$ & Diffuse cytoplasmic & Perinuclear/nuclear \\
\hline Antigen & Proteinase 3 & Myeloperoxidase \\
\hline Clinical association & Wegener's $>$ microscopic PA & Microscopic PA > Wegener's \\
\hline & Necrotizing GN & Necrotizing GN \\
\hline & Crescentic GN & Crescentic GN \\
\hline & & Rheumatoid arthritis \\
\hline & $\alpha$ GBM Ab disease & Drug-induced lupus \\
\hline & & Ulcerative colitis \\
\hline & & Chronic active hepatitis \\
\hline & & Myasthenia gravis \\
\hline False positive & Rare in normals & Juvenile chronic polyarthritis \\
\hline ralse positive & Rare in normals & $1-8 \%$ normals \\
\hline & & ANF positive patients: \\
\hline & & $\begin{array}{l}\alpha \text { Elastase AD } \mathrm{Ab} \\
\alpha \text { Elasta }\end{array}$ \\
\hline & & $\alpha$ Lactoferrin $\mathrm{Ab}$ \\
\hline
\end{tabular}

$\alpha=$ denotes anti; $\mathrm{Ab}=$ antibody; $\mathrm{ANF}=$ antinuclear factor; $\mathrm{PA}=$ polyarteritis; $\mathrm{GN}=$ glomerulonephritis. 
ritis and vasculitis), hypertension (both accelerated phase and chronic) and by a thrombotic microangiopathy. Cell-mediated immunity also plays a role. These processes are not mutually exclusive and probably frequently coexist (Table VIII).

Lupus anticoagulant is an IgG (occasionally IgM) autoantibody to widely distributed complex anionic phospholipid antigens. In vitro these antibodies prolong the partial thromboplastin time but clinically are associated with widespread arterial and venous thrombosis. ${ }^{63}$

A clinical syndrome (Table IX) has evolved which is associated with the lupus anticoagulant both in patients with SLE and others. ${ }^{64}$ Two types of anti-phospholipid antibody have been described. One binds the phospholipid antigens directly and the other requires beta-2-glycoprotein-1 and is particularly associated with thrombosis. ${ }^{65}$

The recognition of this syndrome has important implications for the treatment of lupus nephritis. Therapeutic options now include treatment of acute immune-mediated inflammation, hypertensive vascular disease and thrombotic microangiopathy. Agents useful against the latter include low-dose aspirin, possibly eicosapentaenoic acid (EPA) and suitable antihypertensives such as calcium channel blockers.

\section{v. Treatment of nephrotic syndrome}

Despite expanding knowledge about pathogenesis, therapy remains largely empirical. The three histological lesions most often associated with the nephrotic syndrome will be briefly discussed.

Minimal change nephrotic syndrome Minimal change is the commonest cause of nephrotic syn-

Table VIII Mechanisms in lupus nephropathy

\begin{tabular}{l}
\hline \multicolumn{1}{c}{ Renal lesions of SLE } \\
\hline Glomerular \\
Proliferation (IC \pm CMI?) \\
Focal necrosis (IC, HT) \\
Thrombosis (TM) \\
Sclerosis (end stage) \\
Arteriolar \\
Vasculitis \pm necrosis (IC) \\
Vasculitis \pm fibrinoid necrosis (HT, TM) \\
Arterial \\
Atherosclerosis \\
Arteriosclerosis (HT, TM, end stage) \\
Venous \\
Renal vein thrombosis (NS + TM) \\
Interstitial tissues \\
Acute interstitial nephritis (CMI, IC) \\
Ischaemia (HT, TM)
\end{tabular}

IC = Immune complex; HT = hypertension; $\mathrm{TM}=$ thrombotic microangiopathy; $\mathrm{NS}=$ nephrotic syndrome; $\mathrm{CMI}=$ cell-mediated immunity .
Table IX Anti-phospholipid syndrome

\section{Obstetric}

Recurrent spontaneous abortions (placental thrombosis)

Venous thrombosis

Recurrent deep venous thrombosis

Pulmonary emboli

Pulmonary hypertension

Budd-Chiari syndrome

Arterial lesions

Peripheral gangrene

Mesenteric artery occlusion

Cardiac manifestations

Endocarditis and valvular lesions

Atrial myxoma like lesions

Multiple small coronary occlusions

(pseudocardiomyopathy)

Renal lesions

Glomerular thrombosis

Arteriolar and arterial thrombosis

Renal vein thrombosis

Proteinuria

Hypertension

Renal insufficiency

CNS manifestations

Migraine

Epilepsy

Chorea

Multi-infarct dementia

Retinal artery occlusion

Pseudo-multiple sclerosis

Livedo reticularis

(With cerebral thrombosis $=$ Sneddon's syndrome) Thrombocytopenia

drome in children. Cyclosporin $A$ is now an $\overrightarrow{\vec{O}}$ acceptable alternative to steroids for inducing a 3 remission. It does not reduce the incidence of $\supset$ relapses unlike cyclophosphamide. Cyclosporin $A$ 훔 is also of value in maintaining a remission either $-\vec{O}$ alone or with low-dose steroids. ${ }^{66}$

Membranous glomerulonephritis Membranous glomerulonephritis is the commonest cause of $\delta$ nephrotic syndrome in adults. Treatment is prob- $₹$ ably best reserved for patients with heavy pro- 을 teinuria, severe hypoalbuminaemia and impaired renal function. Children and adults with asymptomatic membranous glomerulonephritis do not warrant immunosuppressive treatment. There is no $\sigma$ consensus about to the best and safest regime. $\tilde{O}$ Intravenous methylprednisolone followed by oral $N_{\omega}$ steroids can induce a remission and may preserve 0 renal function. ${ }^{67}$ Duration of therapy may be an important factor in efficacy. A cyclical regime has $\frac{D}{\mathbb{C}}$ been developed based on monthly cycles of $\stackrel{\oplus}{+}$ chlorambucil followed by a month of steroids $\square$ initiated with intravenous pulse methylprednisolone. This has been shown in a controlled trial to $\stackrel{\square}{\square}$ be of benefit. ${ }^{68} \mathrm{~A}$ regime involving 6 months $\stackrel{\mathbb{Q}}{\mathbb{Q}}$ 
therapy with cyclophosphamide followed by 2 years of warfarin and dipyridamole showed a reduction in proteinuria in the treatment group. ${ }^{69}$ The use of intravenous immunoglobulin appears promising. ${ }^{70}$

Focal segmental glomerulosclerosis (FSGS) FSGS accounts for $10 \%$ of cases of nephrotic syndrome in children and $20 \%$ in adults. Only a minority of patients enter remission with steroids. ${ }^{71}$ Cyclosporin A can induce a partial remission, ${ }^{72}$ but relapse on cessation of therapy is common. Vascular lesions associated with focal segmental glomerulosclerosis may be accelerated by cyclosporin A which is not suitable for long-term use in glomerulonephritis because of its nephrotoxic potential. Analogies between focal segmental glomerulosclerosis and atherosclerosis have emphasized the use of other therapies such as angiotensin converting enzyme (ACE) inhibitors and lipid lowering drugs.

Adjunctive treatments in the management of nephrotic syndrome Control of hypertension is essential and there is increasing evidence that the use of ACE inhibitors may confer additional benefits over and above other anti-hypertensive agents. ACE inhibitors by themselves can significantly reduce proteinuria in nephrotic syndrome. Care should be taken not treat patients who are hypovolaemic. Control of hyperlipidaemia in patients with persistent proteinuria may reduce the long-term risks of atherosclerosis and preserve renal function. The observation that plasma lipoprotein-a, an independent risk factor for coronary heart disease, may be raised in patients with proteinuria, adds further impetus to the need to control the dyslipidaemia associated with this condition. ${ }^{73}$ Dietary advice together with the HMG CoA reductase inhibitors represent the current best treatment approach. Chan et al. treated 14 patients with nephrotic syndrome with lovostatin for 6 months. ${ }^{74}$ One patient developed rhabdomyolysis and one patient severe hypertriglyceridaemia. Total cholesterol fell by $31 \%$ and LDL cholesterol by $43 \%$. In the group as a whole there was no change in proteinuria or glomerular filtration rate although those patients with well preserved pretreatment glomerular filtration rate showed an increase suggesting that early intervention might help preserve renal function. Lovostatin treatment for 12 weeks in diabetics also showed a marked reduction in total cholesterol and LDL cholesterol, but no effect on proteinuria or creatinine clearance. ${ }^{75}$ Clearly much longer term larger studies are required. vi. The use of intravenous immunoglobulin (i.v. Ig)

Intravenous immunoglobulin (i.v. Ig) was first reported to increase platelet counts in idiopathic thrombocytopenic purpura. In 1984 it was shown to be effective in Kawasaki disease ${ }^{76}$ and is now the treatment of choice. Its use has recently been expanded to include the multi-system vasculitides ${ }^{77}$ membranous glomerulonephritis ${ }^{70}$ and the antiphospholipid syndrome. ${ }^{78}$ A multi-centre trial is currently in progress to assess the efficacy of i.v. Ig in the multi-system vasculitides.

Several theories have been advanced to explain the mechanism of action. Intravenous Ig may produce reversible blockade or down regulation of Fc receptors on the cells of the reticuloendothelial system. Alternatively it may contain anti-idiotypic antibodies that suppress autoantibody production. ${ }^{79,80}$

\section{Diabetic nephropathy}

Diabetic nephropathy accounts for increasing numbers of patients on renal replacement programmes. The resulting vast economic and social burden has stimulated inquiry into means of retarding disease progression.

\section{i. Predictors of progressive nephropathy}

The concept that microalbuminuria (the excretion of small amounts of albumin in the albustix negative range) is an important predictor of progressive nephropathy, is now well established. Some problems of definition have been resolved. A urinary albumin excretion rate of between $20-200 \mu \mathrm{g} /$ minute in a timed overnight sample or an albumin to creatinine ratio of $2-20 \mathrm{mg} / \mathrm{mmol}$ in an early morning specimen are commonly accepted criteria. ${ }^{81}$ Lower levels of albumin excretion may also be predictive of renal damage. ${ }^{82}$

The importance of microalbuminuria as a predictor of progressive renal disease has been underlined by the clear associations which have been demonstrated with structural renal damage. Patients with microalbuminuria have increased basement membrane thickening and more mesangial expansion compared with normoalbuminuric patients. ${ }^{83}$ The concept has also emerged that excretion of abnormal amounts of protein might itself cause glomerular damage and contribute to the downward spiral of renal function in diabetic and other proteinuric nephropathies. ${ }^{84}$

Diabetics with microalbuminuria also have elevated blood pressures compared with their normoalbuminuric counterparts. ${ }^{85}$ There is a complex relationship between these two factors and the progression of renal damage. Clearly both micro- 
proteinuria and hypertension can result from renal damage inflicted by the metabolic derangements of diabetes. Both may accelerate progression of renal disease. They are not independent since hypertension aggravates microalbuminuria. Recently it has been suggested that hypertension may play a more fundamental role. Some studies have shown a higher incidence of parental hypertension in diabetics with nephropathy compared to those without, suggesting that a genetic predisposition to hypertension may be an important determinant of progression.

This notion gained support from studies demonstrating significantly increased red cell sodiumlithium countertransport $(\mathrm{Na}-\mathrm{Li} \mathrm{CT})$, a marker for essential hypertension, in diabetics with nephropathy compared to those without. ${ }^{72,86}$ It was also demonstrated that this abnormality preceded the onset of clinical nephropathy and correlated with hyperfiltration, ${ }^{87}$ itself a possible marker of impending clinical nephropathy. Recently, however, a number of studies have cast doubt on these findings, suggesting variously that the abnormality is confined to a subgroup of patients with diabetic nephropathy, ${ }^{88}$ that it is a characteristic of the diabetic process itself ${ }^{89}$ and that it does not exist at all in this setting. ${ }^{90}$ It is difficult to reconcile these diverse findings. A recent study has shown that $\mathrm{Na}-\mathrm{Li} \mathrm{CT}$ activity in red cells is dramatically higher post-prandially compared with the fasting state. ${ }^{91}$ This study confirmed that $\mathrm{Na}-\mathrm{Li} \mathrm{CT}$ activity is elevated in diabetic nephropathy, though, in the post-prandial state, a modified method using a higher external sodium concentration was required to demonstrate it.

A number of other factors have been implicated in the progression of diabetic renal disease including protein intake, hyperfiltration and lipid abnormalities. There is some evidence for the former, in that dietary protein restriction has been shown to reduce the rate of progression of established nephropathy. ${ }^{92}$ There is little evidence though, that the other influences mentioned above, operate as independent risk factors. There is, however, little doubt that the major forces influencing progression are microalbuminuria and hypertension.

\section{ii. Treatment}

Established nephropathy Anti-hypertensive treatment is of proven benefit in preventing the progression of established nephropathy. There is now some evidence for the concept that ACE inhibitors may confer some specific benefit, additional to those obtained by use of conventional anti-hypertensive agents. In a long-term prospective study, treatment with enalapril plus frusemide resulted in a significantly slower rate of decline of renal function in patients with insulin-dependent diabetes than treatment with metoprolol plus $\stackrel{0}{0}$ frusemide, in the face of a comparable reduction in blood pressure..$^{93} \mathrm{~A}$ similar result was obtained $\frac{2}{3}$ when enalapril plus conventional therapy was $\stackrel{8}{\not}$ compared with placebo plus conventional therapy.. in non-insulin-dependent diabetics with nephropathy. ${ }^{94}$ In both studies the protective effect was $\stackrel{\vec{F}}{+}$ biphasic. The initial 6 months of therapy was? characterized by a more rapid fall in glomerular $\frac{\bar{\sigma}}{\bar{D}}$ filtration rate in the enalapril group, with the $\frac{\bar{\sigma}}{5}$ protective effect emerging in the later periods of $\mathscr{\complement}$ study. Although these data are suggestive of a specific benefit of ACE inhibitors in diabetic neph- $\vec{O}$ ropathy, other studies have shown no such effect ${ }^{95}$. and the results of ongoing trials are awaited.

Other avenues of treatment have been explored. There is some evidence that protein and phosphate 8 restriction may be useful, ${ }^{92}$ but the benefits are probably small in relation to those obtained with 8 anti-hypertensive therapy and may not be additive. There is little evidence that improved diabetic $\vec{\omega}$ control reduces the rate of progression of estab- $r$ lished nephropathy. However, dramatic histolo- $\sigma$ gical improvements were seen after transplantation 을 of kidneys affected by diabetic nephropathy into $\overrightarrow{ }$ non-diabetic recipients. ${ }^{96}$ Successful pancreas transplantation has also been shown to be associated with less severe nephropathy in kidneys previously transplanted into diabetic patients This testifies to the vast gap in quality separating. the degree of control achieved by our treatmen regimes and that associated with normal glucose homeostasis.

Incipient nephropathy Improved metabolic control can retard the progression from microalbuminuria to clinical proteinuria. Conventional anti-hypertensive therapy has a similar protective effect, as do ACE inhibitors. Whether ACE inhibitors confer specific protection, in addition to that afforded by their anti-hypertensive effect, has been the subject of intense enquiry. Evidence in 3 favour of such a specific effect is accumulating. The 8 addition of an ACE inhibitor to conventional anti-hypertensive therapy in microalbuminuric dia- $\mathrm{O}$ betics produced a significant reduction in the urinary albumin excretion rate, with no change in glomerular filtration rate or blood pressure assessed by 24 hour ambulatory monitoring. ${ }^{98}$ In nor- $\odot$ motensive patients, treatment with captopril also $N$ demonstrated a significant anti-proteinuric effect $\underset{\mathrm{W}}{ }$ when compared to placebo, though blood pressure $O$ fell slightly in the captopril-treated group. ${ }^{99} \mathrm{~A}_{0}$ meta-analysis of published studies of different $\stackrel{\varnothing}{\Phi}$ anti-hypertensive agents in microalbuminuric and $\stackrel{\oplus}{\stackrel{\oplus}{+}}$ overtly proteinuric diabetics demonstrated that 0 treatment with an ACE inhibitor resulted in a $\stackrel{O}{\circ}$ greater anti-proteinuric effect for a similar blood $\stackrel{\mathbb{D}}{2}$ pressure fall. ${ }^{100}$ Interestingly treatment with nifedi- 
pine produced an increase in proteinuria, a finding which is consistent with its known effects on renal haemodynamics.

\section{Polycystic kidneys}

Clinical features The clinical spectrum of adult autosomal dominant polycystic kidney disease (APKD) has been widened in recent years to involve other organs, perhaps indicating a common defect in connective tissue or ground substance (Table X). The most serious of these associated pathologies is the presence of intracranial aneurysms. Chapman et al. ${ }^{103}$ studied 92 young subjects with APKD and found an incidence of $4 \%$, a four-fold increase over the general population. They recommended high-resolution computed tomographic (CT) scanning as a relatively noninvasive safe screening test. Nuclear magnetic resonance angiography will probably prove superior.

Is screening for unruptured intracranial aneurysms in APKD justified? The early mortality rate of a ruptured intracranial aneurysm is in excess of $50 \%$. Conventional angiography carries an appreciable morbidity and mortality as does surgical intervention. At present it does not seem possible to identify high-risk patients as familial clustering of aneurysms has not been confirmed. There does seem to be a marked intrafamilial variation in phenotypic expression. ${ }^{108}$ Furthermore

Table X Clinical spectrum of APKD (Gabow, 1990) ${ }^{101}$

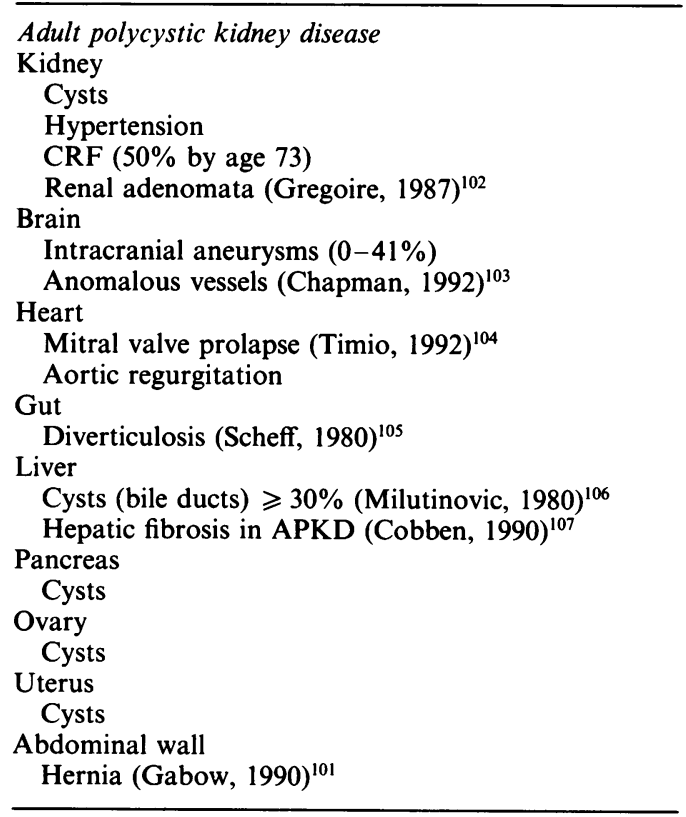

about $25 \%$ of patients with aneurysms will have multiple aneurysms. The probability of rupture of an asymptomatic aneurysm in adult polycystic kidney disease is unknown. The size of the aneurysm $(>10 \mathrm{~mm})$ is related to rupture risk. Some authors have recommended elective surgery in men under the age of 69 and women under the age of 75 with aneurysms over $10 \mathrm{~mm}$ in diameter. ${ }^{109}$ The decision to operate will have to incorporate such factors as local expertise and the surgical accessibility of the aneurysm. In patients who have already survived aneurysm rupture, the indication for surgery is much stronger.

Screening for APKD There are at least two distinct genetic inheritances for APKD. One is on the short arm of chromosome 16 and linked to the alpha-globin gene (APKD1) and another appears to be on chromosome 2 (APKD2). The clinical presentation of APKD in those cases not linked to chromosome 16 is different with patients presenting much later in life with cysts and chronic renal failure. The limitations of pre-natal and family screening techniques for APKD have recently been reviewed. ${ }^{110}$ To be reliable a large kindred spanning several generations should be available for study.

Cyst growth Only one to two nephrons contribute to cyst formation. Tissue culture work suggests that cyst growth is due to an enhanced capacity of tubular epithelial cells to proliferate. Epidermal growth factor provokes an exaggerated proliferative response in culture experiments and has been found in cyst fluid. In a mouse model of recessive polycystic kidney disease, increased expression of several oncogenes has been detected. ${ }^{111}$ Cyst growth depends on the presence of secretion by the epithelial cells which is enhanced by factors that increase cyclic AMP and is suppressed by factors that inhibit it. In human cyst tissue there appears to be altered epithelial cell polarity with the sodium/potassium ATPase pump located on the apical border of the cells and thus lining the inner wall of the cyst. It has also been shown that activation of the renin angiotensin system enhances cyst growth in an animal model. ${ }^{112}$

Extracellular matrix The simplest hypothesis that explains at least in part the renal and extrarenal manifestations of APKD is that the fundamental defect is of basement membrane or extracellular matrix structure. Early changes in the kidney include splitting and reduplication of basement membrane with more advanced abnormalities being seen in the basement membrane around cysts. A wide range of abnormalities in composition of extracellular matrix has been demonstrated but no single defect has been clearly identified. $^{113}$ 
Treatment of APKD Hypertension develops early in some patients with APKD even before there is significant renal impairment. There appears to be activation of the renin angiotensin system early in the course of the disease. ${ }^{114}$ Renovascular resistance is increased and effective renal plasma flow (ERPF) reduced. Treatment with ACE inhibitors has been shown to reduce the elevated renal vascular resistance without changing the glomerular filtration rate. Filtration fraction (GFR/ERPF) fell, indicating a rise in ERPF. Mean arterial blood pressure also fell. In normal family controls ACE inhibition produced no significant changes. ${ }^{114}$ It was then suggested that there is inappropriate activation of the renin angiotensin system for the state of the extracellular fluid volume, ${ }^{115}$ and thence that ACE inhibition may have a beneficial effect on progression. Long-term trials are clearly needed. Recently there has been some renewed interest in cyst drainage. Pain can be relieved without deleterious effect on the rate of progression. ${ }^{116}$

\section{Chronic renal failure}

\section{Atherosclerotic renal artery stenosis}

\section{Introduction}

Atherosclerotic renal artery stenosis (ARAS) is underdiagnosed in life, often inadequately investigated and frequently managed inappropriately.

\section{Incidence}

The precise incidence of ARAS is unknown. It has been estimated that about 105 patients per million per year develop ARAS. Clearly the prevalence depends on the population being studied. Fourteen per cent of our patients with end-stage chronic renal failure over the age of 55, have ARAS. ${ }^{117}$ Where the renal arteries have been seen during coronary angiography or lower limb angiography, the incidence of ARAS has been reported at $19 \%$ and $42 \%$, respectively. ${ }^{118,119}$ In non-insulindependent diabetics with an elevated plasma creatinine the incidence of ARAS is about $40 \%{ }^{120}$

\section{Clinical features}

It is clear that ARAS can often be asymptomatic or overshadowed by the clinical manifestations of atheroma in other major arteries. Before diagnosing asymptomatic ARAS it is worth considering what constitutes a normal plasma creatinine. In young adults a plasma creatinine of $60 \mu \mathrm{mol} / 1$ represents a GFR of approximately $120 \mathrm{ml} /$ minute. For each doubling of plasma creatinine there is a halving of GFR. Thus a plasma creatinine $\stackrel{\text { जी }}{0}$ that appears only slightly elevated, for example $150 \mu \mathrm{mol} / 1$, represents a loss of over half the total $\frac{2}{3}$ renal function. Similarly the criteria for what is $\stackrel{\mathbb{Q}}{2}$ considered to be an elevated blood pressure need to $c$ be revised downwards in the light of recent studies $\ddot{\Rightarrow}$ in older patients. Blood pressures in excess of $\stackrel{\vec{P}}{+}$ $160 / 90 \mathrm{mmHg}$ in the over $60 \mathrm{~s}$ probably warrant $\bar{?}$ investigation and treatment. ${ }^{121,122}$ It is just this group of patients with minimally elevated plasma creatinine and hypertension over the age of 60 , in $\triangle$ which atherosclerotic disease in general is most likely to be found.

The clinical presentations of ARAS include? hypertension (often of less than 5 years duration). $\vec{\omega}$ The hypertension may be 'newly worse' and more $\Omega$

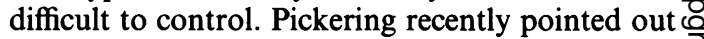
that hypertension with recurrent episodes of left 3 . ventricular failure is commonly associated with 8 ARAS. ${ }^{123}$ The expanding use of ACE inhibitors has $\infty$ revealed unsuspected cases of ARAS and in one $\vec{\omega}$ series this condition accounted for $4 \%$ of all $r$ patients presenting with acute renal failure. ${ }^{124}$ Fre- $\sigma$ quently ARAS is part of a more generalized disease $\frac{}{5}$ process with atheroma of the coronary and cere- $\vec{\overrightarrow{ }}$ bral circulations as well as lower limb and sometimes mesenteric ischaemia.

In order to diagnose patients with ARAS a high degree of clinical suspicion is essential. Hyperte sion in an arteriopath with a missing pulse or $\frac{7}{8}$ bruit (not necessarily a renal bruit) should alert the clinician to the possibility of underlying ARAS.

\section{Diagnosis}

The pre- and post-captopril renogram is a helpful preliminary screen. ${ }^{125} \mathrm{~A}$ baseline renogram (DTPA or Mag III) is repeated on a subsequent day, one hour after $25 \mathrm{mg}$ of oral captopril. The ischaemic kidney or kidneys elaborate angiotensin II (A II). A II constricts the efferent glomerular arteriole preserving glomerular filtration pressure despite reduced perfusion. Abolition of intrarenal A II $\delta$ production reduces glomerular filtration but less so renal blood flow. This is reflected in a change in the $\mathrm{O}$ renogram which shows an increased disparity of divided renal function and a prolonged time to peak activity in the ischaemic kidney. In patients in whom the clinical probability of ARAS is very high of and the baseline renogram typical, the post- $N$ captopril scan may be omitted and intra-arterial N digital subtraction angiography (IA-DSA) undertaken. Intravenous DSA does not give the surgeon or radiologist enough anatomical detail on which $\frac{C}{\mathscr{D}}$ to plan intervention. Magnetic resonance imaging (MRI) angiography may replace conventional 0 arteriography. Even with smaller catheters and $\bar{O}$ lower doses of contrast IA-DSA may produce $\mathbb{D}$ significant morbidity both with respect to local $\mathbb{D}$ 
trauma to the punctured artery and more remote complications (emboli and contrast nephrotoxicity). Selected patients need special precautions, for example, good hydration (left ventricular function permitting) and low dose dopamine. It is sometimes necessary to dialyse patients after angiography if renal failure or cardiac decompensation occur. Clinicians should be aware of the cholesterol emboli syndrome which presents like a vasculitis (livedo reticularis, fever and acute renal failure). Hypocomplementaemia and eosinophilia are typical. ${ }^{26}$ The syndrome may occur spontaneously or after angiography in patients with atherosclerosis.

Investigation must include an assessment of both coronary and cerebral circulations as well as a detailed assessment of the risk factors and causes of atherosclerosis. Critical coronary or cerebral lesions may need attention before the renal artery. ${ }^{127}$

\section{Intervention in ARAS}

Can aggressive investigation and intervention in ARAS be justified? There are three main points that justify an active approach.

1. Natural history of ARAS. Serial angiogram studies have shown that ARAS is a progressive disease. Forty per cent of patients with unilateral ARAS develop contralateral disease over 4 to 5 years. Forty per cent of severe stenoses $(>75 \%)$ occlude over a 2 year period. ${ }^{128}$

2. Developments in interventional techniques. (a) Percutaneous translumenal angioplasty (PTA). For lesions that are more main trunk than ostial, PTA has a place. In selected patients with high surgical risk, PTA may be the only intervention available. In experienced hands and with careful patient selection this technique can be safe and effective. Recurrence of the stenosis may occur so that follow-up and repeat PTA may be required. (b) Renal revascularization by bypass procedures. There have been great strides made in vascular surgery over the last two decades. It is safer to bypass severe aortic/ostial lesions than to attempt a formal repair. It is worth emphasizing that ostial ARAS is really an aortic disease. A right renal artery stenosis can be bypassed using the hepatic or gastroduodenal artery (with or without a segment of graft). The splenic artery may be used for a left renal artery. Synthetic grafts can be inserted higher up the aorta and implanted beyond the renal artery narrowing. These procedures have significantly reduced the morbidity and mortality of renal artery surgery. ${ }^{129}$

3. Preservation of renal function. The classical view of renal artery surgery was that it was carried out to cure hypertension or to render it easier to control. A more important consideration is preservation of renal function. Patients with ARAS not unusually present clinically after one kidney has virtually ceased to function and the second kidney is now failing. Appropriate intervention can avoid such patients requiring dialysis.

\section{Significance of renal artery lesions}

The finding of a renal artery narrowing does not necessarily mean that the lesion is haemodynamically significant. A stenosis of $70-75 \%$ or greater is usually significant. A unilaterally small kidney, particularly if perfusion and uptake are delayed, also suggests a significant stenosis. A positive captopril renogram or a rise in plasma creatinine with an ACE inhibitor suggests that the stenosis is impairing perfusion and function. Renal vein renins are sometimes of value.

\section{Surgical intervention}

With the proviso that cerebral or coronary vascular surgery may be needed first, renal revascularization is of proven value both for the control of blood pressure and the preservation/salvage of renal function. Operating on kidneys less than $8 \mathrm{~cm}$ in length in which there is no perfusion or nephrogram, is unlikely to be successful. Regrograde filling of the renal artery on angiography is an encouraging sign indicating good collateral circulation despite an apparently totally occluded renal artery. A perioperative renal biopsy can be helpful in identifying kidneys in which the glomeruli are non-sclerosed and therefore capable of functioning. PTA and surgical revascularization should not be seen as mutually exclusive. Failure of one technique in a given patient may be followed by success of the other, There are promising early reports of the use of stents placed after PTA for ostial lesions. ${ }^{130,131}$

\section{Medical intervention}

Atherosclerosis is a generalized and progressive disease. A case can be made for the intensive medical management of all patients with ARAS, whether or not intervention is undertaken. The aetiological factors for atherosclerosis are well known and the cellular and molecular basis of atherosclerosis is being delineated in ever greater detail. Evidence is accumulating that atheroma can be reversed in other vascular beds so why not in ARAS? ${ }^{132-134}$ The most important prerequisite for all medical therapy is that the patient should stop smoking. Perhaps the second most important factor is obsessional control of the blood pressure. Here the choice of agents may be critical with ACE inhibitors and beta blockers being contraindicated. In the over $65 \mathrm{~s}$ is diet and control of hyperlipidaemia likely to help? Certainly patients should 
be advised to diet to ideal weight and avoid sodium rich foods if hypertensive. With the arrival of safe and effective lipid-lowering agents, patients with proven ARAS should be studied in a properly designed randomized controlled trial of intensive medical therapy.

\section{Erythropoietin}

The erythropoeitin (Epo) revoluton was triggered by the isolation and cloning of the Epo gene ${ }^{135,136}$ and subsequent clinical use of recombinant human Epo to treat the anaemia of patients with chronic renal failure requiring haemodialysis. ${ }^{137,138}$ The last few years have seen an explosion in our understanding of the biology and clinical applications of Epo.

The human Epo gene is located on chromosome 7 where it is encoded as a single copy gene consisting of five exons separated by four introns. ${ }^{139}$ Besides the kidney, the liver is a wellestablished site of Epo production. The probable site of production in the kidney is the endothelial cells of peritubular capillaries, though there is some evidence that interstitial cells and tubular cells may also be involved. ${ }^{140}$ Epo secretion is stimulated by hypoxia by a mechanism which involves an oxygen sensor located near the proximal tubules. It is not known whether the oxygen-sensing cells are the cells which secrete Epo. The oxygen sensor has recently been shown to be a heme protein which triggers Epo production when in the deoxy conformation. DNA sequences both upstream and downstream of the Epo gene are required for the hypoxic response in liver and kidney. ${ }^{140}$ The target cells for the action of Epo are committed erythroid progenitor cells in the bone marrow, which have specific Epo receptors. ${ }^{141}$

\section{Dosage and route of administration}

The initial clinical trials of Epo demonstrated dramatic improvements in the anaemia of haemodialysed patients. ${ }^{137,138}$ The doses and route of administration used in these initial studies were necessarily empirical and much subsequent work in this area has focused on optimizing these. Studies of the pharmacokinetics of Epo after an intravenous dose have shown that the mean half-time for clearance from the plasma is about 5-7 hours. ${ }^{142-145}$ The apparent volume of distribution is close to the plasma volume. ${ }^{142,146}$ Renal clearance accounts for less than $3 \%$ of total body clearance. ${ }^{146}$ The peak concentration achieved after a subcutaneous dose is 12.5-20 times lower than that after the same intravenous dose. Absorption from the subcutaneous site is complete after about 120 hours with a bioavailability of about $30 \% .{ }^{144}$

It appears though that the quality of the erythropoietic response depends on the maintenance of adequate plasma levels rather than the absolute height of the peak plasma level, ${ }^{145}$ and numerous $\cong$ studies have demonstrated the superiority of the 3 subcutaneous route in clinical practice. ${ }^{145,147-149} \mathbb{\Omega}$ Thrice weekly subcutaneous injection is as effective. as thrice weekly intravenous injection but permits a $\overrightarrow{\vec{F}}$ dose reduction in the range of $30-50 \%$. Once weekly subcutaneous injection is equally effective but permits no dose reduction. ${ }^{150}$

The response to therapy is dose dependent but there are great variations in response between patients. ${ }^{138}$ Most patients require $50-200 \mathrm{IU} / \mathrm{kg} / \%$ week given in two or three subcutaneous doses to achieve and maintain target haemoglobin levels. Therapy requires to be individualized and based on rigorous monitoring, and a mathematical model for Epo dosing has been proposed. ${ }^{151}$ In spite of the growing experience in the clinical use of Epo, recent studies suggest that underdosing is endemic. . $^{147,152}$

Many studies have demonstrated the effective- $\infty$ ness of Epo in continuous ambulatory peritoneal $\vec{\omega}$ dialysis (CAPD) patients. ${ }^{153-155}$ The subcutaneous of route has been most commonly used and has been shown to be more effective than the intraperitoneal route. ${ }^{156,157}$ The optimum frequency of administration is not yet known and may be subject to variation between individuals though once weekly treatment has been shown to be effective. ${ }^{158,159}$ There are suggestions that CAPD patients may be more responsive to Epo than haemodialysis pक्षे tients perhaps because of chronic blood losses in the latter group. ${ }^{160}$

There is an increasing experience with the use of Epo in predialysis patients, ${ }^{161-166}$ in whom the dose range and frequency for subcutaneous administration have been found to be similar to those required in dialysed patients. There were initial fears that therapy with Epo may be associated with an increase in the rate of progression of renal failure This was based on the propensity of Epo to produce an exacerbation of hypertension and a reduction in effective renal plasma flow. These fears appear to be largely unfounded ${ }^{162-166}$ though careful monitoring of blood pressure is essential and the initiation of therapy with small doses has been advocated. ${ }^{166}$

Patients with haemoglobinopathies and endstage renal failure often respond to Epo but may require substantially larger doses. ${ }^{167}$ Those with end-stage renal failure complicating myeloma may also respond. ${ }^{168,169}$

\section{Beneficial effects of Epo}

The beneficial effects of Epo can usually be related $\stackrel{\oplus}{\stackrel{\oplus}{+}}$ to the improvement of anaemia. There may be 7 other direct effects including alterations of haemostatic parameters and improvement of platelet function though even these may be related to the 
rise in haematocrit. ${ }^{170-172}$ Many studies have shown improvements in quality of life scores. ${ }^{173-177}$ Regression of left ventricular hypertrophy in spite of the tendency to exacerbate hypertension has been another important finding. ${ }^{178-181}$ These and other effects of Epo are alluded to in Table XI.

\section{Adverse effects of Epo}

Treatment with Epo is usually very well tolerated and there are few serious adverse effects. Nevertheless a number of possible problems may arise (Table XII). Increased blood pressure is the most commonly reported of these and occurs in about one third of patients with renal failure. The risk appears maximal in the early stages of treatment when the haematocrit is increasing. Nevertheless there appears to be no clear association with the dose of Epo nor with the rate of rise of haematocrit. ${ }^{182}$ Blood volume does not change on Epo treatment ${ }^{183}$ so is unlikely to be a hypertensive mechanism. Haemodynamic studies though, have repeatedly shown an increase in systemic vascular resistance coupled with a reduction in cardiac output during therapy with Epo. ${ }^{183-185}$

Factors which may be important in the rise in the systemic vascular resistance are shown in Table XIII. The major factor appears to be a rise in the blood viscosity during Epo treatment which is largely related to the rise in haematocrit, though the fluidity of the red cells may also be disturbed. ${ }^{186,187}$ Another contributory factor may be loss of the vasodilatory response to hypoxia. ${ }^{188}$ Other factors appear less important though alterations in sympathetic function have been described. ${ }^{189,190}$ If the rise in systemic vascular resistance observed during Epo therapy was accompanied by an appropriate reduction in cardiac output, no change in blood pressure would be observed. There is some evidence that cardiac output remains inappropriately high in those patients who develop hypertension, ${ }^{183}$ perhaps due to baroreceptor dysfunction and impaired myocardial compliance.

Grand mal seizures were reported in the early

Table XI Reported beneficial effects of treatment with Epo in chronic renal failure

\section{Effect}

Quality of life

Exercise capacity

Cognitive function

Neuromuscular function

Sexual potency

Regression of LVH

Improved haemostasis

Improved pituitary function

Reduced cytotoxic antibody titres
Table XII Possible adverse effects of treatment with Epo

\author{
Hypertension \\ Fits \\ Increased clotting \\ Flu-like syndrome \\ Reduced dialyser efficiency
}

Table XIII Factors associated with the rise in systemic vascular resistance during Epo therapy

Increased blood viscosity

Increased haematocrit

Decreased red cell fluidity

Loss of hypoxic vasodilatation

Direct vasoconstrictor effect of Epo

Activation of neurohumoral systems

Renin-angiotensin system

Sympathetic system

Imbalance of local endothelial factors

EDRF

Endothelin

clinical studies of Epo, ${ }^{138}$ though subsequent controlled studies showed no difference in prevalence between the treated and placebo groups. ${ }^{191}$ Nevertheless, seizures do occur in some patients early in the course of Epo therapy at a time when haematocrit and blood pressure are increasing rapidly, and most of these patients appear to have hypertensive encephalopathy. ${ }^{192}$ Hypertensive encephalopathy is usually the result of a breakdown in cerebral autoregulation, ${ }^{193}$ resulting in hyperperfusion, damage to the blood-brain barrier, exudation of protein, and focal cerebral oedema. Cerebral blood flow is usually reduced in response to the rising haematocrit during Epo therapy, ${ }^{194,195}$ but whether this adaptation is always complete remains to be established.

An increase in the number of thrombotic events has been reported during Epo therapy, though the finding is not substantiated by placebo-controlled studies. ${ }^{196}$ As haematocrit increases, vascular access particularly PTFE and bovine grafts, may be at increased risk and low-dose aspirin prophylaxis has been recommended. Other haemostatic changes occur ${ }^{170-172}$ but there is no evidence that Epo produces a hypercoagulable state. ${ }^{191}$

Epo and the efficiency of dialysis

An increase in haematocrit reduces plasma water flow through the dialyser leading to a decrease in solute clearance and ultrafiltration rate. This effect on solute clearance is dependent on the diffusabilty of the solute across the semipermeable membrane. The clearances of easily diffusible solutes, such as 
urea, are less affected than those of less readily diffusible solutes. This is because the fall in plasma water flow is offset by an increased delivery of intracellular water (red cells contain $80 \%$ water), from which solutes such as urea can readily diffuse. Clearances of less readily diffusible substances, such as creatinine, and those whose intracellular concentrations are maintained by active transport processes, such as potassium and phosphate, are much more susceptible to a rising haematocrit. ${ }^{197}$ The magnitude of the expected reduction in dialyser efficiency consequent on an increase in haematocrit from $20 \%$ to $33 \%$ would be expected to be of the order of $16 \%$ for poorly diffusible substances and less for those readily diffusible, since this is the proportional reduction of plasmacrit (from $80 \%$ to $67 \%$ ).

A number of studies have addressed the clinical relevance of these theoretical considerations. In chronic haemodialysis employing conventional membranes, there was no change in $\mathrm{Kt} / \mathrm{V}$ (urea) and protein catabolic rate (see p. 532) consequent on a mean increment in (a measure of dialysis efficiency) haematocrit from 21 to $34 \%$. However, predialysis potassium concentrations were significantly higher, the use of phosphate binders increased (as did the heparin dose), and the dialyser efficiency for creatinine, potassium and phosphate decreased by $15 \%, 9 \%$ and $17 \%$, respectively. Similar changes were seen in patients undergoing high-efficiency dialysis. ${ }^{198}$ Hence it appears that only small changes to dialysis schedules, heparin dose and phosphate binder dose are required to counteract the effects of clinically relevant increments in haematocrit.

The effect of rising haematocrit on solute clearance and ultrafiltration rate in CAPD patients is less well studied. The available studies have shown no effect on either solute clearance or ultrafiltration, ${ }^{199,200}$ decreased solute clearances, ${ }^{201}$ and surprisingly increased ultrafiltration. ${ }^{202}$

\section{Resistance to Epo}

Most patients with chronic renal failure respond well to Epo therapy. However, a small proportion of patients require much larger than average doses and a tiny minority do not respond at all. The common causes of poor response (termed Epo resistance) are shown in Table XIV. By far the commonest cause of poor response is iron deficiency which may predate Epo therapy (in which case the indication for Epo is suspect), or occur as a consequence of a previous good response. The diagnosis of iron deficiency is difficult in patients with chronic renal failure. Both the serum ferritin level and transferrin saturation may be misleading. The transferrin saturation and iron-binding capacity correlate better with Epo response than
Table XIV Factors associated with resistance to Epo treatment

Iron deficiency

Occult blood loss

Vitamin deficiency

Folate

B12

B6

Inflammatory states

Infection

Surgery

Secondary hyperparathyroidism

Aluminium intoxication

Haemoglobinopathies

Chronic haemolysis

Malignancy

Protein-calorie malnutrition

does serum ferritin, suggesting that the functional availability of iron in the plasma may be more $\vec{\omega}$ important than the actual size of the body iron of stores in determining response. ${ }^{203}$ Determination of the percentage of hypochromic red-cells may be a more sensitive index of iron deficiency. ${ }^{181}$ Almost all patients require supplementation with iron in order to maintain a response and many require iron by the intravenous route. The suggestion has been made that suboptimal doses of Epo markedI\$ reduce serum ferritin levels. ${ }^{204}$

The other major cause of poor response to Epo the presence of inflammation due to infection, surgical interventions, autoimmune disorders or malignancy. ${ }^{205} \mathrm{~A}$ reduction in iron availability for haem production from iron stores in the endoplasmic reticulum, ${ }^{205,206}$ and increased cytokine production leading to decreased Epo production or endorgan resistance to the action of $\mathrm{Epo}^{207,208}$ are possible explanations for this phenomenon. An interesting exception is the increased response to Epo which occurs in the context of viral hepatitis. This may be attributable to increased production of Epo by newly formed hepatocytes. ${ }^{209}$

\section{Mineral metabolism and renal bone disease}

Pathophysiology of secondary hyperparathyroidism

$1,25(\mathrm{OH})_{2} \mathrm{D}_{3}$ directly suppresses parathyroid hormone synthesis ${ }^{210}$ and deficiency of $1,25(\mathrm{OH})_{2} \mathrm{D}_{3}$ is considered to be a major stimulus to hyperparathyroidism in chronic renal failure (CRF). However, in early CRF levels of $1,25(\mathrm{OH})_{2} \mathrm{D}_{3}$ are normal. Recently it has emerged that $1,25(\mathrm{OH})_{2} \mathrm{D}_{3}$ receptor density on parathyroid cells is reduced in CRF,${ }^{211,212}$ though the binding affinity of the receptor for $1,25(\mathrm{OH})_{2} \mathrm{D}_{3}$ is unchanged. ${ }^{212}$ Uraemic toxins may reduce genomic synthesis of 
$1,25(\mathrm{OH})_{2} \mathrm{D}_{3}$ receptors by inhibiting the interaction of the hormone-receptor complex with nuclear chromatin. ${ }^{213}$ This reduced receptor density probably accounts for the resistance of the parathyroid glands to suppression by $1,25(\mathrm{OH})_{2} \mathrm{D}_{3}$ which is encountered in renal failure. ${ }^{214}$ Administration of $1,25(\mathrm{OH})_{2} \mathrm{D}_{3}$ increases the number of vitamin $\mathrm{D}$ receptors in a dose-dependent fashion, ${ }^{215}$ thus restoring the regulation of parathyroid hormone secretion toward normal, and increasing the sensitivity of the glands to calcium. In line with this, the elevated set point for parathyroid hormone suppression by calcium in CRF is reduced by the administration of $1,25(\mathrm{OH})_{2} \mathrm{D}_{3}{ }^{216,217}$

Skeletal resistance to the calcaemic action of parathyroid hormone may also contribute to the genesis of secondary hyperparathyroidism in CRF. Deficiency of $1,25(\mathrm{OH})_{2} \mathrm{D}_{3}$ and hyperphosphataemia are factors which augment this resistance. ${ }^{218}$ Parathyroidectomy reverses the problem. In spite of this it does not seem that the resistance is due to down regulation of parathyroid hormone receptors in response to high circulating levels of parathyroid hormone. ${ }^{219}$ Calcitonin may be involved since its absence normalizes the calcaemic response to parathyroid hormone in uraemic rats. ${ }^{220}$

Phosphate retention is also thought to play a role in the development of secondary hyperparathyroidism in CRF. The mechanisms have been thought to be either direct physicochemical interaction of phosphate with calcium leading to relative hypocalcaemia, and phosphate-induced suppression of $1,25(\mathrm{OH})_{2} \mathrm{D}_{3}$ synthesis. The finding that phosphorus restriction can reverse hyperparathyroidism in uraemia independently of changes in serum calcium and calcitriol levels is therefore intriguing. ${ }^{221}$

\section{Therapy of renal bone disease}

Treatment and prevention of phosphate accumulation in CRF remains unsatisfactory. ${ }^{222}$ Problems with aluminium accumulation place great restrictions on the use of aluminium-containing phosphate binders. Calcium carbonate is a useful alternative ${ }^{223}$ but hypercalcaemia occurs frequently. 224 Calcium acetate has theoretical advantages, ${ }^{225,226}$ but these have proved difficult to demonstrate clinically, ${ }^{227}$ and hypercalcaemia remains a problem. Lowering of the dialysate calcium concentration has enabled larger doses of calcium-containing phosphate binders to be used, in both haemodialysed and CAPD patients, with less risk of hypercalcaemia and without compromising net calcium balance. ${ }^{228,229}$

Intravenous pulse therapy with $1,25(\mathrm{OH})_{2} \mathrm{D}_{3}$ is effective in suppressing parathyroid hormone levels in patients with severe secondary hyperparathyroidism. ${ }^{230}$ Pulsed therapy proved more effective than continuous treatment in suppressing parathyroid hormone levels in experimental animals, ${ }^{231}$ suggesting that the parathyroid gland is more responsive to peaks than to steady-state levels. It appears though that intermittent oral treatment is as effective as intermittent intravenous treatment. ${ }^{232}$ One of the major problems in treating secondary hyperparathyroidism is the remarkable capacity of the parathyroids to escape from control. It seems that tolerance to pulsed calcitriol may also emerge after relatively short treatment times. ${ }^{233}$ Other approaches have been used. Oral $24,25(\mathrm{OH})_{2} \mathrm{D}_{3}$ has been shown to suppress parathyroid hormone levels in dialysed patients many of whom had hypercalcaemic hyperparathyroidism. ${ }^{234}$ The synthesis of a non-calcaemic analogue of vitamin D3 is an exciting development. This compound, 22-oxacalcitriol (OCT), has been shown to be as effective as $1,25(\mathrm{OH})_{2} \mathrm{D}_{3}$ in suppressing parathyroid hormone levels, but 100 times less effective in mobilizing bone calcium, and 1000 times less effective in stimulating intestinal calcium transport. ${ }^{235}$ Clearly such compounds have major clinical potential in the treatment of secondary hyperparathyroidism in chronic renal failure.

\section{Adynamic bone disease}

The spectrum of bony abnormalities associated with chronic renal failure has been increased by the description of a novel form of adynamic bone disease. ${ }^{236}$ Adynamic changes in bone were formerly thought to occur in this group of patients entirely as a result of aluminium toxicity. Now similar histological changes have been described in patients in whom there is no evidence of aluminium accumulation. This idiopathic form of the disease may account for up to $24 \%$ of cases. ${ }^{237}$ The problem may be more common in elderly patients, in diabetics, and in CAPD patients. ${ }^{237}$ The entity has also been seen in predialysis patients and the suggestion made that overtreatment with calcium supplements and active vitamin D compounds may predispose to the problem by oversuppressing parathyroid hormone levels to a degree inappropriate for the prevailing level of renal function. ${ }^{238}$ Histologically the disease is characterized by markedly reduced bone turnover, with a paucity of osteoid, bone cells and a significant reduction in active remodelling sites and tetracycline uptake. ${ }^{237}$ The clinical relevance of these histological abnormalities await firm definition. Patients with the problem do seem to have a propensity to develop hypercalcaemia, and may be at increased risk of microfracture. $^{237}$ 


\section{Dialysis}

\section{Adequacy}

All currently available modes of renal replacement therapy, with the exception of successful renal transplantation, fall a long way short of the gold standard 'to clean blood and biological fluids to a degree comparable to normal renal function'.239 These inherent limitations of dialysis therapies dictate the need for some criteria of adequacy of therapy, difficult though they are to define.

\section{Adequacy of haemodialysis and related techniques}

'Traditional' haemodialysis treatment employed long hours ordained by the 'square metre-hour' hypothesis, ${ }^{240}$ the rationale of which was to provide adequate clearance of 'middle molecules'. Treatment was monitored by clinical assessment and by the measurement of predialysis blood urea and serum creatinine levels. Adequacy, at least as far as small molecular weight solute clearance was concerned, was not a critical issue.

Now, however, the question of adequacy has been brought into sharp focus by pressures, largely economic, to shorten haemodialysis times. This trend has taken place without any adjustment to the monitoring process and has resulted in significantly increased mortality in haemodialysis patients, especially in the USA. ${ }^{241,242}$ This implies that some of the basic requirements for adequacy have remained unfulfilled and yet have been overlooked by traditional monitoring methods.

Clinical assessment remains an important tool for monitoring adequacy, but inadequate therapy can remain undetected when guided solely by clinical parameters. ${ }^{243,244}$ 'Static' biochemical parameters such as predialysis urea and creatinine concentrations have also been found wanting. When protein intake is deficient, the predialysis urea may remain low in spite of inadequate dialysis, and a low predialysis urea has been found to be predictive of high mortality. ${ }^{245}$ Similarly it has been demonstrated that predialysis creatinine levels are inversely related to mortality. ${ }^{246,247}$ In the dialysis population, with relatively constant rates of creatinine removal, the major determinant of the serum creatinine level is the creatinine generation rate, ${ }^{247} \mathrm{a}$ reflection of somatic protein content. ${ }^{248}$ This implies that, in this population, creatinine levels are an indicator of nutritional status. This notion is supported by the strong correlation between predialysis creatinine and serum albumin, which is a strong predictor of mortality in all populations. ${ }^{249}$

There are a number of alternative methods of defining and monitoring adequacy. The most prominent of these is urea kinetic modelling (UKM) which received considerable impetus from its evaluation in the National Cooperative Dialysis Study (NCDS). ${ }^{250,251}$ A re-examination of this study ${ }^{252}$ showed a lower morbidity in patients: (1) with a $K_{\mathrm{t}} / V>0.8$ (in thrice weekly dialysed patients), where $K=$ total urea clearance (residual renal clearance plus clearance by dialyser $(\mathrm{ml} /$ minute), $t=$ dialysis time (minutes), and $V=$ the urea distribution volume ( $=$ total body water $(\mathrm{ml})$ ); and (2) with a protein catabolic rate (PCR) from 0.8 to $1.4 \mathrm{~g} / \mathrm{kg} /$ body wt/day. PCR is derived from the urea generation rate and in stable patients is considered to be an index of the adequacy of protein intake. There is a strong correlation between $K_{\mathrm{t}} / V$ and PCR which may suggest that the poor control of the uraemic state resulting from inadequate dialysis causes the retention of appetitesuppressing uraemic toxins, resulting in malnutrition and increased morbidity and mortality. ${ }^{252,253}$

UKM is becoming increasingly used to prescribe and monitor the delivery of haemodialysis. The targets are derived from the NCDS, that is, $K_{\mathrm{t}} / V$ $>1.0$ and $P C R=0.8-1.2$. Whilst it is widely recognized as a potentially useful tool there remain areas of concern. The choice of urea as a marker solute is subject to criticism, but there is no ideal marker solute, ${ }^{239}$ and urea at least has the advantage of reflecting protein catabolism, the products of which are central to the concept of uraemic toxicity. Its use also has the substantial backing of the NCDS. ${ }^{250-252}$ Whilst the parameter $K_{\mathrm{t}} / V$ is becoming well accepted, the exact means of cal culating it for routine clinical purposes still inspire debate. ${ }^{254-257}$ There is also some discussion about what constitutes an optimal target $K_{\mathrm{t}} / V$ for chronic haemodialysis patients and the view has been expressed that morbidity continues to decline with increasing $K_{\mathrm{t}} / V$ with no obvious optimum. ${ }^{258}$ The remarkable survival figures from Tassin, ${ }^{259}$ achieved with a mean $K_{\mathrm{t}} / V=1.67$, may constitute some support for this view, though there are other possible explanations including case-mix and control of hypertension. Whether the same target $K_{\mathrm{t}} / V$ is appropriate for stable chronic patients (such as those studied in the NCDS) and sicker, more catabolic patients is also unclear. ${ }^{239}$

The use of UKM to maintain adequacy when dialysis times are shortened can be highly beneficial. ${ }^{260}$ The safety margin though is small and rigorous monitoring is required to ensure adequate delivery. Rapid treatments may expose a further problem. The degree of post-dialysis urea rebound is greater after such treatments because of the limiting effect of intercompartmental shifts on urea clearance. ${ }^{261}$ This effect will lead to underdialysis unless allowance is made by the appropriate timing of post-dialysis blood sampling or by modification of the single-pool based UKM parameters to account for these two-pool effects. ${ }^{261}$ The dialysis membrane used may also have important effects. 
Standard cellulosic membranes were employed in the NCDS. It has been suggested that high-flux dialysers with better biocompatibility characteristics require less rigorous urea clearance. ${ }^{253}$

Concern has also been expressed that the two major parameters derived from UKM are not independent since they are mathematically derived from similar parameters. This counsels caution in interpreting the correlation between them. ${ }^{239}$ Finally, and perhaps most importantly, the use of these criteria of adequacy are not yet supported by long-term studies with mortality as the end point. This will be the definitive test.

\section{Adequacy of CAPD}

In contrast to haemodialysis, the adequacy of CAPD has received little attention. Most patients on this treatment are prescribed a standard regime of 8 litres of fluid daily. Taking into account the wide range of patient size, and their considerable diversity in residual renal function, it would be suprising if there were not wide variations in dialysis adequacy. The available studies confirm that CAPD patients received a wide range of dialysis dose expressed as $K_{\mathrm{t}} / V^{263-265}$

It is also apparent that dialysis adequacy declines with increasing time on dialysis, and that this is related to a decline in residual renal function ${ }^{263-265}$ rather than in the parameters of peritoneal mass transfer. ${ }^{264,265}$ There are also highly significant correlations between $K_{\mathrm{t}} / V$ and PCR normalized for total body water. ${ }^{263-265}$

There are two related but major difficulties in interpreting UKM data in CAPD patients. First is its lack of validation by clinical outcome measures. Recently, however, three studies have demonstrated an inverse correlation of $K_{\mathrm{t}} / V$ and hospitalization rate. ${ }^{264-266}$ There are no studies relating CAPD adequacy and mortality. Secondly there is considerable debate on the values of $K_{\mathrm{t}} / V$ consistent with adequacy. Theoretical considerations based on the 'peak hypothesis" ${ }^{267}$ suggest that for CAPD to produce the same steady-state concentration of urea as the midweek prehaemodialysis concentration, a daily $K_{\mathrm{t}} / V$ of 0.3 is required (Figure 1). There is a paucity of data but patients with a daily $K_{\mathrm{t}} / V<0.25$ had significantly more hospitalizations than those with a higher $K_{t} / V^{265}$

A worrying feature is the finding of a decline of $K_{\mathrm{t}} / V$ with loss of residual renal function. There is a limited capacity in CAPD to compensate for loss of residual renal function by increasing dialysate volumes. This implies that there must be considerable doubt about the long-term viability of the technique especially in patients with larger than average body mass.

\section{Other aspects of adequacy}

The discussion above has been dominated by the concept of biochemical adequacy. There are clearly

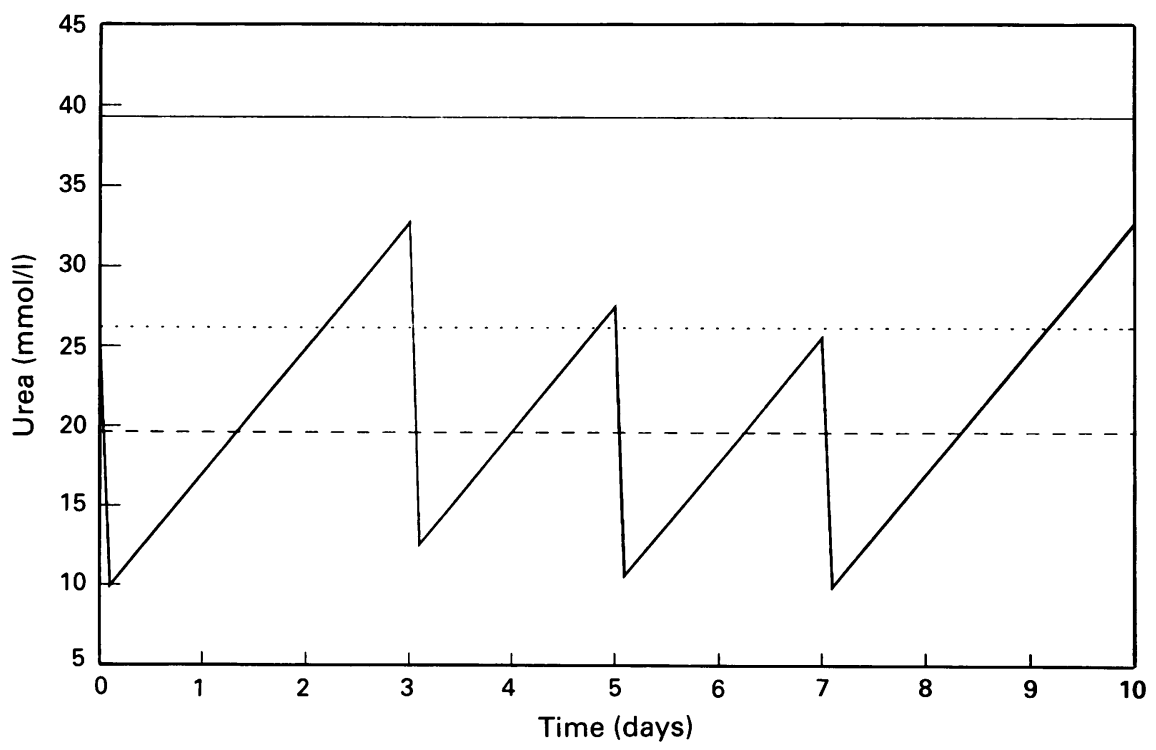

Figure 1 Interrelationships of adequacy parameters in haemodialysis and CAPD. The saw-tooth line represents the blood urea concentration in a typical patient haemodialysed three times weekly with NPCR $=1$ and $K_{t} / V=1$. The horizontal lines represent the situation in CAPD patients with varying adequacy parameters. The horizontal solid line represents a daily $K_{\mathrm{t}} / V=0.2$, the dotted line a daily $K_{\mathrm{t}} / V=0.3$, and the dashed line a daily $K_{\mathrm{t}} / V=0.4$. 
other aspects. Perhaps the most important of these is adequacy of control of salt and water balance and hypertension. There is evidence that in both short hours haemodialysis and CAPD that blood pressure control may be suboptimal and associated with progressive cardiovascular damage. ${ }^{268,269}$ The requirement for adequate control of hypertension may play a significant role in the design of optimal dialysis schedules. After all most dialysis patients die a cardiovascular death.

\section{Dialysis-related amyloidosis}

Dialysis-related amyloidosis is now recognized as a major, and potentially limiting complication of chronic dialysis treatment. The syndrome was recognized in the early $1980 \mathrm{~s}^{270}$ and soon after $\beta_{2}$-microglobulin $\left(\beta_{2} \mathrm{~m}\right)$ was identified as the amyloid precursor protein. ${ }^{271}$ The main clinical features are carpal tunnel syndrome and destructive arthropathy, predominantly affecting large and mediumsized joints, and associated with bone cysts. ${ }^{272}$ The spine is also involved though mechanisms other than amyloid deposition may be of importance in the pathogenesis of the spondyloarthropathy. ${ }^{273,274}$ The incidence of both carpal tunnel syndrome and the osteoarticular lesions increase with the duration of hemodialysis treatment. There is virtually $100 \%$ involvement by $15-20$ years. ${ }^{275,276}$ Age at onset of dialysis is an important predictor, older patients being more likely to develop the problem. ${ }^{277}$ Visceral involvement occurs infrequently, but can have clinical consequences. ${ }^{278}$

The recognition of $\beta_{2} m$ retention as the essential requirement for the development of dialysis-related amyloidosis, has stimulated enquiry into factors affecting its rate of synthesis, release and clearance. $\beta_{2} \mathrm{~m}$ is an 11,800 dalton protein which, as part of the human class 1 major histocompatibility complex, is found on the surface of all nucleated cells. It is also found in neutrophil granules, and is a secretory protein of hepatocytes. Increased synthesis and release into extracellular fluid are mediated by various cytokines including tumour necrosis factor, interleukin-2, and alpha and gamma interferons. High serum levels occur in inflammatory and malignant lymphoproliferative disorders. It is eliminated from the body largely $(95 \%)$ by glomerular filtration and subsequent tubular absorption and degradation, hence its accumulation in renal failure.

The possibility that dialysis specific factors may be important in the accumulation of $\beta_{2} m$ has received much attention. There is growing evidence that haemodialysis incites an inflammatory response, stimulating the cellular release of interleukin-1 and TNF, granulocyte activation with the generation of reactive oxygen species, and comple- ment activation. ${ }^{279-281}$ In addition, there is in vitro $\stackrel{0}{0}$ evidence of increased $\beta_{2} \mathrm{~m}$ production by lym- ̊ phocytes and monocytes harvested at the end of 3 haemodialysis. ${ }^{282}$ Many of these processes were $\stackrel{\mathbb{Q}}{\mathscr{2}}$ more pronounced in or confined to dialysis involv-.. ing cuprophane membranes when compared with $\overrightarrow{\vec{F}}$ dialysis involving newer, more biocompatible membranes, composed of polymethylmethacrylate, polyacrylonitrile or polysulphone. There is, however, very little evidence of $\beta_{2} \mathrm{~m}$ production during clinical haemodialysis when correction is $\varnothing$ made for dialysis-induced changes in extracellular के fluid volume. ${ }^{283-286}$ As well as possible membrane $\vec{\circ}$ effects on $\beta_{2} \mathrm{~m}$ production, the composition and purity of the dialysis fluid may also have a role, since acetate and endotoxin both promote interleukin-1 production. ${ }^{287,288}$

Whilst doubts remain about differences between membranes with respect to their capacity to 6 generate $\beta_{2} \mathrm{~m}$, there is little doubt that a significant $\stackrel{\infty}{\omega}$ clearance of $\beta_{2} \mathrm{~m}$ can be achieved using high flux membranes compared to that achieved by cup- $\vec{\sigma}$ raphane. ${ }^{289,290}$ As well as increased removal of $\beta_{2} \mathrm{~m}$. by filtration through these high flux membranes, there is also evidence of enhanced adsorption of $\overrightarrow{\vec{c}}$

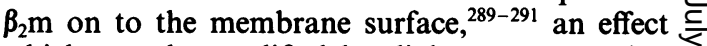
which may be modified by dialyser reprocessing techniques. ${ }^{291}$ Increased $\beta_{2} \mathrm{~m}$ clearance by highl $\mathbb{8}$ permeable membranes may well be clinicalli important, since a large multi-centre retrospectiv. study has shown a decreased incidence of dialysisrelated amyloidosis in patients dialysed using polyacrylonitrile compared to patients dialysed using cuprophane ${ }^{267}$ Haemofiltration has a greater capacity to remove $\beta_{2} \mathrm{~m}$ than even high flux dialysis. $^{292}$

Although experience with long-term CAPD is still limited, there are now a number of reports of dialysis-associated arthropathy occurring in patients treated solely by this modality, ${ }^{293-295}$ and reports of the disease progressing after transfer to CAPD from haemodialysis. ${ }^{187}$ There is significant clearance of $\beta_{2} \mathrm{~m}$ by the peritoneal membrane, ${ }^{296,297}$ which is of the same order as that achieved by high-flux dialysis. Hypertonic exchanges, ${ }^{296}$ and the use of glucose polymer, ${ }^{298}$ both increase peritoneal clearance. There is no evidence of $\beta_{2} \mathrm{~m}$ generation during the dialysis process, though, like haemodialysis, CAPD can induce cellular activation and the release of inflammatory mediators. ${ }^{299} \mathrm{~N}$ The propensity for CAPD patients to develop the N dialysis-related amyloidosis may well be less than that for haemodialysed patients, at least those 0 treated using standard cuprophane membranes, but only further studies will tell.

Recent work has provided further insights into the pathogenesis of the disease, and argues against the role of simple precipitation of $\beta_{2} \mathrm{~m}$ into amyloid-like fibril structures as the sole cause. 
Amyloid fibrils seem to consist not only of intact $\beta_{2} \mathrm{~m}$, but also of proteolysed fragments, at least one of which has also been demonstrated in the plasma of long-term haemodialysed patients. ${ }^{300,301}$ Proteolysis of $\beta_{2} \mathrm{~m}$, perhaps by proteases released as part of the inflammatory response to haemodialysis, may be important in the development of the disease. On the other hand it has been argued that it is incomplete proteolysis of $\beta_{2} \mathrm{~m}$ which is the necessary condition for amyloid fibril formation, and that inhibition of proteolysis by 'amyloid enhancing factors' such as the anti-protease $\alpha_{2}$ macroglobulin predisposes to the condition. ${ }^{302}$

Treatment options are limited for established disease. Renal transplantation has been shown to limit disease progression ${ }^{294}$ but there is no other effective therapy. Prevention is therefore of the utmost importance. High-flux dialysis using biocompatible membranes, bicarbonate as the buffer and ultrapure water seem rational measures to adopt. ${ }^{303,304}$ Haemodiafiltration offers the best hope of preventing the disease but is an expensive option with currently available technology. The place of CAPD in prevention strategies is presently unknown. Prospective studies are required to evaluate these options perhaps employing recently described radionuclide tracing and imaging of $\beta_{2} \mathrm{~m}$ amyloid deposits to monitor disease progression. ${ }^{305-307}$

\section{Transplantation}

\section{Matching}

Despite the absence of large randomized prospective controlled trials, HLA matching is now accepted as one of the prime determinants of both early and, increasingly importantly, long-term graft survival. ${ }^{308}$ It has also become clear that kidneys that undergo neither a rejection episode nor primary non-function do very much better than those that do. ${ }^{309}$ This observation has been advanced as a justification for intensive induction regimes usually including biological anti-lymphocyte preparations. The impact of DNA typing on transplantation is yet to be felt but graft survival of $90 \%$ may be attainable. ${ }^{310}$ Although with DNA typing matching will become more difficult, it will be more exact.

\section{New drugs}

A variety of new immunosuppressive drugs is being studied both in animal models of transplantation and in pilot studies in man. ${ }^{311}$ It seems likely that some will soon find acceptance in routine clinical practice. ${ }^{311,312}$
FK506

FK506 is a macrolide ${ }^{313}$ which acts in a similar manner to cyclosporin A by blocking the phosphatase activity of calcineurin which leads to a failure of transcription of I12 and other T-cell activation genes. Both cyclosporin A and FK506 enhance the transcription of TGF-b which is a potent inhibitor of I12 stimulated T-cell proliferation. FK506 is more potent in these regards than cyclosporin $A$ and is also a more potent inhibitor of B cells. Nephrotoxicity is a major problem but early reports suggest that hypertension is less of a problem with FK506. The impression is that FK506 may well replace cyclosporin A in liver transplantation but that it is unlikely to do so in renal transplantation. The results of several trials comparing FK506 and cyclosporin A should be available soon.

\section{Rapamycin}

Rapamycin ${ }^{314}$ is also a macrolide and like FK506 binds to FK-binding protein, but this is not its mode of action. It blocks Il2-mediated signal transduction and can block Il2 driven T-cell proliferation. It does not block the induction of II2 gene expression. It is synergistic with cyclosporin $\mathrm{A}$ but antagonistic to FK506. In rats it produces myocardial toxicity.

\section{RS-61443}

This agent ${ }^{315}$ is a semi-synthetic derivative of a fungal antibiotic, mycophenolic acid. It is an inhibitor of purine synthesis, like azathioprine, which it may replace. It is synergistic with cyclosporin A and 15-deoxyspergualine. It does not appear to be marrow toxic. Its major side effects are on the gastro-intestinal tract.

\section{5-Deoxyspergualin (15-DS)}

This agent ${ }^{316}$ is a derivative of spergualin from Bacillus laterosporus. Its mode of action is unknown. It suppresses macrophage function (interleukin 1 production, production of oxygen derived radicals, reduction of class II expression), and decreases cytotoxic $\mathrm{T}$-cell proliferation. It appears more potent than cyclosporin $A$ and may be synergistic with both cyclosporin A and FK506. 15-DS has been shown to reverse established rejections and to prevent their occurrence. It is toxic to bone marrow and may cause gastrointestinal disturbances. 
Table XV Antibodies being used in transplant rejection

\begin{tabular}{|c|c|c|c|c|c|c|c|}
\hline Antibody & Mitosis & $A D C C$ & Modulation & Lysis & $N-K$ cells & $\begin{array}{l}\text { Cytokine } \\
\text { release }\end{array}$ & $\begin{array}{c}\text { Cytokine release } \\
\text { syndrome }\end{array}$ \\
\hline ATG & - & ++ & ? & \pm & $\downarrow \downarrow \downarrow$ & TNF $\alpha$ & ++ \\
\hline OKT3 & ++ & ++ & ++ & - & & $\begin{array}{l}\text { TNF } \alpha \text {, INF } \gamma \\
\text { GMCSF }\end{array}$ & ++++ \\
\hline T10 B9 & \pm & \pm & ++ & + & $\rightarrow$ & TNF $\alpha$, INF $\gamma$ & \\
\hline CAMPATH-1 & - & \pm & - & ++ & $\downarrow \downarrow$ & & ++ \\
\hline 33B3.1 & - & + & $?$ & - & $\rightarrow$ & & - \\
\hline SDZ CHI 621 & - & + & + & - & $\rightarrow$ & & - \\
\hline SDZ CHH 380 & - & + & ++ & - & $\rightarrow$ & $\begin{array}{l}\text { TNF } \alpha \\
\text { Il6 }\end{array}$ & + \\
\hline
\end{tabular}

TNF $\alpha=$ Tumour necrosis factor alpha; INF $\gamma=$ gamma interferon; GMCSF $=$ granulocyte monocyte colony stimulating factor; $\mathrm{ADCC}=$ antibody-dependent cell-mediated cytotoxicity; $\mathrm{NK}=$ natural killer; $\mathrm{ATG}=$ antithymocyte globulin.

- negative or absent; \pm weak or equivocal; + positive or present; $\downarrow$ reduced; $\rightarrow$ no change; $\uparrow$ increased; ? unknown.

Table XVI Immunogenicity of antibodies being used in transplantation

\begin{tabular}{|c|c|c|c|c|c|}
\hline Antibody & aID (\%) & $\begin{array}{l}\text { Immunogenicity } \\
\quad \text { aALLO/aXENO (\%) }\end{array}$ & $\begin{array}{l}\text { Half life } \\
\text { (hours) }\end{array}$ & Specificities (CD) & \\
\hline ATG & - & $70-80$ & $?$ & $\begin{array}{l}\text { HLA DR, LEU-C } \\
45,18,2,4,8\end{array}$ & \\
\hline OKT3 & $30-70$ & $30-100$ & 24 & 3 & రి \\
\hline T10 B9 & 10 & $30-50$ & 4 & 3 & एे \\
\hline CAMPATH-1 & $?$ & 80 & 8 & W52 & ڤે \\
\hline 33 B3 1 & 30 & $80-90$ & 24 & 25 & ગ \\
\hline SDZ CHI 621 & 0 & 0 & 312 & 25 & \\
\hline SDZ CHH 380 & 1.3 & 4.5 & $77-151$ & 7 & \\
\hline
\end{tabular}

HLA = Histocompatibility locus antigen; LEU-C = leucocyte common antigen; aID = anti-idiotypic antibody; aALLO = anti-allotypic antibody; aXENO = anti-xenotypic antibody; $C D=$ cluster determinant.

New biologicals

Molecular biology is producing an increasing range of pure and specific animal antibodies to defined specificities on human lymphocytes. ${ }^{317}$ These antibodies can be chimaerized or humanized. ${ }^{318}$ This additional step, although increasing cost considerably, renders the end product either less or non-immunogenic. Some of the currently available antibodies are summarized in Tables XV and XVI.

\section{Chimaeric antibodies}

Anti-CD7 antibodies, although non-immunogenic, had no significant impact on either the number or onset of rejection episodes in first cadaveric renal allograft recipients. ${ }^{319}$ Chimaeric anti-CD25 antibodies are currently being evaluated. Limited experience with anti-CD4 antibodies indicates that, although these reagents are very potent in animal models, ${ }^{320}$ they may elicit an anti-idiotypic response.

\section{Other MOAB}

Other reagents with effects on lymphocyte adhesion are being developed and evaluated, such as antibodies to CD2, CD8, LFA1, ICAM-1, LFA3. Development is still largely at the stage of animal studies although preliminary results with anti ICAM-1 (CD54) antibodies in humans appear promising. ${ }^{321}$ The mode of action of these anti- $\frac{D}{O}$ bodies varies depending not only on the surface determinant against which the antibody is directed $N$ but also on whether or not the antibody is lytic, depleting or modulating (Table XV). Of con- C siderable clinical importance is the cytokine release $\mathrm{\omega}$ syndrome seen most markedly with OKT3. It now seems likely that antibodies causing the release of $\circ$ TNF $\alpha$ may also predispose to graft thrombosis. ${ }^{322}$

\section{Optimal immunosuppression}

There is still no agreement as to what is the optimal immunosuppressive regime for renal allografts. 
Strategies need to be developed that take into account an early induction phase, an intermediate semi-stable phase of graft acceptance and then a prolonged maintenance phase during which drug toxicity may well be more important than the risk of rejection.

\section{Induction}

The use of a monoclonal anti-CD25 antibody for induction is promising for first transplants. ${ }^{323}$ Second or subsequent transplants may benefit from the use of the more widely reactive polyspecific antibody such as anti-thymocyte globulin. Induction should be tailored in the light of the relative risk of early rejection. Fully matched first grafts have a much lower risk of rejection than poorly matched grafts or second or subsequent transplants. Transplants into the highly sensitized recipient also have an increased risk of early rejection. By targeting the early activation steps of the immune response, using agents effective only against activated lymphocytes, a degree of specificity can be obtained which should not result in an unacceptably high risk of infection.

\section{Maintenance therapy}

Cyclosporin A usually with prednisolone and azathioprine, is the most widely accepted maintenance regime for both the early and intermediate period after grafting. The best regime for long-term therapy is not clear. Steroids can be withdrawn safely in some patients. ${ }^{324}$ Cyclosporin A can be stopped, particularly in those in whom marked or progressive nephrotoxicity is a problem, but there does appear to be a significant risk of rejection episodes occurring in these patients. ${ }^{325}$

\section{References}

1. Birch, D.F. \& Fairley, K.F. Hematuria: glomerular or non glomerular? Lancet 1979, ii: 845-846.

2. Schumann, G.B. \& Schumann, J.L. Microscopic examination of the urinary sediment to differentiate high from low renal bleeding. In: Andreucci, V.E. \& Fine, L.G. (eds). International Yearbook of Nephrology. Springer Verlag, London, 1992, pp. 337-352.

3. Tomita, M., Kitamoto, Y., Nakayama, M.\& Sato, T. A new morphological classification of urinary erythrocytes for differential diagnosis of glomerular haematuria. Clin Nephrol 1992, 37(2): 84-89.

4. Kohler, H., Wandel, E. \& Brunk, B. Acanthocyturia - a characteristic marker for glomerular bleeding. Kidney Int 1991, 40: 115-120.

5. Kon, V. \& Badr, K.F. Biological actions and pathophysiologic significance of endothelin in the kidney. Kidney Int 1991, 40: 1-12.

6. Tomita, K., Ojile, K., Nakanishi, T. et al. Plasma endothelin levels in patients with acute renal failure. $N$ Engl J Med 1989 , 321: 1127.

\section{Treatment of rejection crises}

Steroids still remain the mainstay of treatment of early rejection crises, because of the ease of administration and cost. OKT3 can be used successfully for the treatment of rejection and for the rescue of patients from steroid-resistant rejection crises. $^{326}$ Polyclonal anti-lymphocyte or antithymus globulin similarly can be used for rescue. Anti-CD25 antibodies do not appear effective for the reversal of rejection episodes. ${ }^{327}$

\section{Long-term medical management of renal transplants}

The principal cause of death after successful transplantation is a cardiovascular or cerebrovascular event. It is now time that transplant physicians assessed cardiovascular risk factors more thoroughly. It is interesting to note that not only are many transplant patients hypercholesterolaemic but that lipoprotein-a is also markedly elevated..$^{328}$ Preliminary studies suggest that cyclosporin A may be particularly prone to raise lipoprotein-a. Interactions (for example, rhabdomyolysis) between lipid lowering agents and cyclosporin $\mathrm{A}$ have to be borne in mind when prescribing.

Long-term medical management of renal transplants must include a determined attempt to reduce and stop smoking, obsessional blood pressure control, using agents not associated with dyslipidaemias and diet. These measures may well help to retard or even prevent chronic vascular rejection which has many pathogenetic similarities with atherosclerosis. An up-to-date review of the common ground between atherosclerosis and chronic vascular rejection can be found in the proceedings of the Fourth Alexis Carrel Conference. ${ }^{329}$

7. Shibouta, Y., Suzuki, N., Shino, A. et al. Pathophysiological role of endothelin in acute renal failure. Life Sci 1990, 46: 1611-1618.

8. Wetzels, J.F.M., Burke, T.J. \& Schrier, R.W. Prevention and attenuation of acute renal failure. Curr Opin Nephrol Hypertens 1992, 1: 133-140.

9. Luscher, T.F., Bock, H.A., Yang, Z. \& Diederich, D. Endothelium-derived relaxing and contracting factors: Perspectives in nephrology. Kidney Int 1991, 39: 757-590.

10 Rees, D.D., Palmer, R.M.J. \& Moncada, S. The role of endothelium-derived nitric oxide in the regulation of blood pressure. Proc Natl Acad Sci USA 1989, 86: 3375-3378.

11. Conger, J.D., Robinette, J.B. \& Schrier, R.W. Smooth muscle calcium and endothelium-derived relaxing factor in the abnormal vascular responses of acute renal failure. J Clin Invest 1988, 82: 532-537. 
12. Martin, W., Villani, G.M., Jothianadan, D. \& Furchgott, R.F. Selective blockade of endothelium dependent and glyceryl trinitrate-induced relaxation by haemoglobin and by methylene blue in the rabbit aorta. $J$ Pharmacol Exp Ther 1985, 232: 708-716.

13. Martin, W., Villani, G.M., Jothianadan, D. \& Furchgott, R.F. Blockade of endothelium-dependent and glyceryl trinitrate-induced relaxation of rabbit aorta by certain ferrous haemoproteins. J Pharmacol Exp Ther 1985, 233: 679-685.

14. Nava, E., Palmer, R.M.J. \& Moncada, S. Inhibition of nitric oxide in septic shock: how much is beneficial? Lancet 1991, 338: $1555-1557$.

15. Petros, A., Bennet, D. \& Vallance, P. Effect of nitric oxide synthase inhibitors on hypotension in patients with septic shock. Lancet 1991, 338: 1557-1558.

16. Epstein, M. Calcium antagonists and the kidney: implications for renal protection. Kidney Int 1992, 36 (Suppl): S66-S72.

17. Shimizu, T., Kawabata, T. \& Nakamura, M. Protective effect of a novel calcium blocker, S-312-d, on ischemic acute renal failure in rat. $J$ Pharmacol Exp Ther 1990, 255: 484-490.

18. Michael, U. \& Lee, S.M. The role of calcium antagonists in nephrotoxic models of renal failure. In: Epstein, M. \& Loutzenhiser, R. (eds) Calcium Antagonists and the Kidney. Hanley \& Belfus, 1993.

19. Neumayer, H.H., Junge, W., Kufner, A. \& Wenning, A. Prevention of radiocontrast-media-induced nephrotoxicity by the calcium channel blocker nitrendipine: A prospective randomised clinical trial. Nephrol Dial Transplant 1989, 4: $1030-1036$

20. Wagner, K., Albrecht, S. \& Neumayer, H. Prevention of post-transplant acute tubular necrosis by the calcium antagonist diltiazem: A prospective randomised study. Am J Nephrol 1987, 7: 287-291.

21. Frei, U., Harms, A., Bakovic Alt, R., Pichlmayr, R. \& Koch, K.M. Calcium channel blockers for kidney protection. $J$ Cardiovasc Pharmacol 1990, 16 (Suppl 6): S11-S15.

22. Neumayer, H.H., Blossei, N., Seherr Thohs, U. \& Wagner, $\mathrm{K}$. Amelioration of postischaemic acute renal failure in conscious dogs by human atrial natriuretic peptide. Nephrol Dial Transplant 1990, 5: 32-38.

23. Conger, J.D., Falk, S.A. \& Hammond, W.S. Atrial natriuretic peptide and dopamine in established acute renal failure in the rat. Kidney Int 1990, 40: 21-28.

24. Pollock, D.M. \& Opgenorth, T.J. Beneficial effect of the atrial natriuretic factor analog $\mathrm{A} 68828$ in postischemic acute renal failure. J Pharmacol Exp Ther 1990, 255: 1166-1169.

25. Bayati, A., Nygren, K., Kallskog, O. \& Wolgast, M. The effect of loop diuretics on the long-term outcome of post-ischaemic acute renal failure in the rat. Acta Physiol Scand 1990, 139: 271-279.

26. Coimbra, T.M., Cieslinski, D.A. \& Humes, H.D. Epidermal growth factor accelerates renal repair in mercuric chloride nephrotoxicity. Am J Physiol 1990, 259: F438-F443.

27. Storck, M., Hartl, W.H., Zimmerer, E. \& Inthorn, D. Comparison of pump-driven and spontaneous continuous haemofiltration in postoperative acute renal failure. Lancet 1991, 337: 452-455.

28. Peterman, J.H., Julian, B.A., Kirk, K.A. \& Jackson, S. Selective elevation of monomeric IgA1 in IgA nephropathy patients with normal renal function. Am J Kidney Dis 1991, 18(3): $313-319$.

29. Cederholm, B., Wieslander, J., Bygrew, P. et al. Circulating complexes containing IgA and fibronectin in patients with primary IgA nephropathy. Proc Natl Acad Sci USA 1988, 85: $4865-4868$

30. Cosio, F.G., Mahan, J.D. \& Sedmak, D.D. Experimental glomerulonephritis induced by antigen that binds to glomerular fibronectin. Am J Kidney Dis 1990, 15: 160-168.

31. Wang, M.-X., Walker, R.G. \& Kincaid-Smith, P. Endothelial cell antigens recognised by IgA autoantibodies in patients with IgA nephropathy: partial characterization. Nephrol Dial Transplant 1992, 7: 805-810.
32. Jennette, J.C., Wieslander, J., Tuttle, R., Falk, R.J. \& The Glomerular Disease Collaborative Network. Serum IgA fibronectin aggregates in patients with IgA nephropathy and Henoch-Schonlein purpura: diagnostic value and pathogenic implications. Am J Kidney Dis 1991, XVIII (4): 466-471.

33. Kincaid-Smith, P., Laver, M.C., Fairley, K.F. \& Mathews, D.C. Dipyridamole and anticoagulants in renal disease due to glomerular and vascular lesions. A new approach to therapy. Med J Aust 1970, 1: 145-151.

34. Shirato, I., Tomino, Y. \& Koike, H. Detection of 'activated platelets' in the urinary sediments using a scanning electron microscope in patients with IgA nephropathy. Am J Nephrol 1990, 10: $186-190$.

35. Taira, K., Hewitson, T.D. \& Kincaid-Smith, P. Urinary platelet factor four (PF4) levels in mesangial IgA glomerulonephritis and this basement membrane disease. Clin Nephrol 1992, 37(1): 8-13.

36. Alambartine, E., Sabatier, J.-C., Guerin, C., Berliet, J.-M. \& Berthoux, F. Prognostic factors in mesangial IgA glomerulonephritis: an extensive study with univariate and multivariate analysis. Am J Kidney Dis 1991, 18(1): 12-19.

37. Okada, H., Suzuki, H., Konishi, K., Sakaguchi, H. \& Saruta, T. Histological alterations in renal specimens as indicators of prognosis of IgA nephropathy. Clin Nephrol 1992, 37(5): 235-238.

38. Nagy, J., Milteny, M., Dobos, M. et al. Tubular proteinuria in IgA glomerulonephritis. Clin Nephrol 1987, 27: 76-78.

39. Dohi, K., Iwano, M., Muraguchi, A. et al. The prognostic significance of urinary interleukin 6 in IgA nephropathy. Clin Nephrol 1991, 35(1): 1-5.

40. Wyatt, R.J., Julian, B.A., Woodford, S.Y. et al. C4A deficiency and poor prognosis in patients with IgA nephropathy. Clin Nephrol 1991, 36(1): 1-5.

41. Woo, K.T., Lau, Y.K., Lee, G.S.L., Wei, S.S. \& Lim, C.HO Pattern of proteinuria in IgA nephritis by SDS-PAGE clinical significance. Clin Nephrol 1991(a), 36(1): 6-11.

42. Woo, K., Lee, G., Lai, Y., Chiang, G. \& Lim, C. Effects of triple therapy in IgA nephritis a follow-up study 5 years later. Clin Nephrol 1991, 36: 6-66.

43. Schena, F.P., Montenegro, M. \& Scivittaro, V. Metaanalysis of randomized controlled trials of patients with primary IgA nephropathy or Berger's disease. Nephrol Dial Transplant 1990, Suppl 1: 47-52.

44. Kobayashi, Y., Kiki, Y., Fujii, K., Kurokawa, A., Kamiyana, M. \& Tateno, S. IgA nephropathy: heterogeneous clinical pictures and steroid therapy in progressive cases. Seminars in Nephrology 1987, 7: 382-385.

45. Lai, K., Lai, F., Ho, C. \& Chan, K. Corticosteroid therapy in IgA nephropathy with nephrotic syndrome. A long term controlled trial. Clin Nephrol 1986, 26: 174-180.

46. Lai, K.N., Lai, F.M.M., Li, P.K. \& Vallance-Owen, J. Cyclosporin treatment of IgA nephropathy: a short term controlled trial. BMJ 1987, 295: 1165-1168.

47. Bennet, W.M., Walker, R.G. \& Kincaid-Smith, P. Treatment of IgA nephropathy with Eicosapentanoic Acid (EPA): a two year prospective trial. Clin Nephrol 1989, 31: $128-131$

48. Lee, G.S., Woo, K.T. \& Lim, C.H. Controlled trial of dipyridamole and low dose warfarin in patient with IgA nephritis with renal impairment. Clin Nephrol 1989, 31(5) 276.

49. Chan, M., Kwan, S., Chan, K. \& Young, L. Controlled trial of antiplatelet agents in mesangial IgA glomerulonephritis. Am J Kidney Dis 1987, 9: 417-421.

50. Egido, J., Rivera, F., Sancho, J., Barat, A. \& Hernando, L. Phenytoin in IgA nephropathy: a long term controlled trial Nephron 1984, 38: 30-39.

51. Glassock, R. Treatment of immunologically mediated glomerular disease. Kidney Int 1992, 42(538): S121-S126.

52. Pusey, C.D., Rees, A.J., Evans, D.J., Peters, D.K. \& Lockwood, C.M. Plasma exchange in focal necrotising glomerulonephritis without anti-GBM antibodies. Kidney Int 1991, 40: 757-763. 
53. Bourgoignie, J.J. \& Pardo, V. HIV associated nephropathies. N Engl J Med 1992, 327(10): 729-730.

54. Luke, D.R., Sarnoski, T.P. \& Dennis, S. Incidence of microalbuminuria in ambulatory patients with acquired immunodeficiency syndrome. Clin Nephrol 1992, 38(2): 69-74.

55. Rao, T.K. Clinical features of human immunodeficiency virus associated nephropathy. Kidney Int 1991, 40(S35): S13-S18.

56. Katz, A., Bargman, J.M., Miller, D.C., Guo, J.-W., Ghali, V.S. \& Schoeneman, M.J. IgA nephritis in HIV positive patients: a new HIV associated nephropathy. Clin Nephrol 1992, 38(2): 61-68.

57. Kimmel, P.L., Phillips, T.M., Ferreira-Centeno, A., FarkasSzallasi, T., Abraham, A.A. \& Garrett, C.T. Brief report: idiopathic IgA nephropathy in patients with human immunodeficiency virus infection. N Engl J Med 1992, 327(10): $702-706$

58. Hebert, L.A., Cosio, F.G. \& Neff, J.C. Diagnostic significance of hypocomplementemia. Kidney Int 1991, 39: $811-821$

59. Saxena, R., Bygren, P., Cederholm, B., Wieslander, J. Circulating anti-entactin antibodies in patients with glomerulonephritis. Kidney Int 1991, 39: 996-1004.

60. Schulze, M., Donadio, J.V,. Pruchno, C.J. et al. Elevated urinary excretion of the C $5 \mathrm{~b}-9$ complex in membranous nephropathy. Kidney Int 1991, 40: 533-538.

61. Kallenberg, C.G.M. \& Tervaert, J.W.C. Antineutrophil cytoplasmic antibodies (ANCA): new tools in the diagnosis and follow-up of necrotising glomerulonephritis and vasculitis. In: Andreucci, V.E. \& Fine, L.G. (eds) International Yearbook of Nephrology. Springer-Verlag, London, 1992, pp. 313-336.

61a.Ulmex, M., Rautmann, A. \& Gross, W.L., Immunodiagnostic aspects of autoantibodies against myeloperoxidase. Clin Nephrol 1992, 37(4): 161-168.

62. Gaskin, G., Savage, C.O.S., Ryan, J.J. et al. Anti neutrophil cytoplasmic antibodies and disease activity during longterm follow-up of 70 patients with systemic vasculitis. Nephrol Dial Transplant 1991, 6: 689-694.

63. Mackworth-Young, C.G., Loizou, S. \& Walport, M.J. Antiphospholipid antibodies and disease. $Q J$ Med 1989, 72(269): 767-777.

64. D'Agati, V., Kunis, C., Williams, G. \& Appel, G.B. Anti-cardiolipin antibody and renal disease: a report of three cases. J Am Soc Nephrol 1990, 1: 777-784.

65. Hunt, J.E., McNeil, H.P., Morgan, G.J., Crameri, R.C. \& Krilis, S.A. A phospholipid-beta2-glycoprotein-1 complex is an antigen for cardiolipin antibodies occurring in autoimmune disease but not with infection. Lupus 1993 (in press).

66. Meyrier, A. Treatment of glomerular disease with cyclosporin. Nephrol Dial Transplant 1989, 4: 923-931.

67. Short, C., Soloman, L., Gokal, R. \& Mallick, N.P. Methyl prednisolone in patients with membranous nephropathy and declining renal function. $Q J$ Med 1987, 65: 929-940.

68. Ponticelli, C., Zucchelli, P. \& Passerini, P. A randomized trial of methylprednisolone and chlorambucil in idiopathic membranous nephropathy. $N$ Engl J Med 1989, 320: 8-13.

69. Murphy, B.F., McDonald, I., Fairley, K.F. \& KincaidSmith, P.S. Randomized controlled trial of cyclophosphamide, warfarin and dipyridamole in idiopathic membranous glomerulonephritis. Clin Nephrol 1992, 37(5): 229-234.

70. Palla, R., Cirami, C., Panichi, V., Bianchi, A.M., Parrini, M. \& Grazi, G. Intravenous immunoglobulin therapy of membranous nephropathy: efficacy and safety. Clin Nephrol 1991, 35(3): 98-104.

71. Walker, R.G. \& Kincaid-Smith, P. The effect of treatment of corticosteroid resistant idiopathic (primary) focal and segmental hyalinosis and sclerosis (focal glomerulosclerosis) with cyclosporin. Nephron 1990, 54: 117-121.

72. Walker, J.D., Tariq, T. \& Viberti, G. Sodium-lithium countertransport activity in red cells of patients with insulin-dependent diabetes and nephropathy and their parents. Br Med J 1990, 301: 635-638.
73. Thomas, M.E., Freestone, A., Varghese, Z., Persaud, J.W. \& Moorhead, J.F. Lipoprotein (a) inpatients with proteinuria. Nephrol Dial Transplant 1992, 7: 597-601.

74. Chan, P.C.K., Robinson, J.D., Yeung, W.C., Cheng, I.K., Yeung, H.W.D. \& Tsang, M.T.S. Lovastatin in glomerulonephritis patients with hyperlipidaemia and heavy proteinuria. Nephrol Dial Transplant 1992, 7: 93-99.

75. Biesenbach, G. \& Zazqornik, J. Lovastatin in the treatment of hypercholesterolaemia in nephrotic syndrome due to diabetic nephropathy stage IV-V. Clin Nephrol 1992, 34(6): 274-279.

76. Furusho, K., Kamiy, T. \& Nakano, H. High dose intravenous gammaglobulin for Kawasaki disease. Lancet 1984 , i: $1055-1058$.

77. Jayne, D.R.W., Davies, M.J., Fox, C.J.V., Black, C.M. \& Lockwood, C.M. Treatment of systemic vasculitis with pooled intravenous immunoglobulin. Lancet 1991, 337: 1137.

78. Carreras, L.O., Perez, G.N. \& Vega, H.R. Lupus anticoagulant and recurrent fetal loss: successful treatment with gamma globulin. Lancet 1988, ii: 393-395.

79. Kaveri, S.V., Dietrich, G., Jobin, D., Rossi, F., Sultan, Y., Lockwood, C.M. \& Kazatchkine, M.D. Idiotipic modulation of autoimmunity by therapeutic human immunoglobulin preparations (IVIg). In: Grunfeld, J.P., Bach, J.F., Kries, H. \& Maxwell, M.H. (eds). Advances in Nephrology Mosby Year Book, St Louis, 1992, Vol. 21, pp. 239-346.

80. Rossi, F., Jayne, D.R.W., Lockwood, C.M. \& Hazatchkine, H.D. Anti-idiotypes in normal human polyspecific IgG for therapeutic use and in the remission sera of patients with systemic vasculitis. Clin Exp Immunol 1991, 830: 2980-3030.

81. Mogensen, C.E. Management of renal disease and hypertension in insulin-dependent diabetes with emphasis on early nephropathy. Curr Opin Nephrol Hypertens 1992, 1: 106-115.

82. Chase, H.P., Marshall, G., Garg, S.K., Harris, S. \& Osberg, I. Borderline increase in albumin excretion rate and relation to glycaemic control in subjects with type 1 diabetes. Clin Chem 1991, 37: 2048-2052.

83. Walker, J.D., Close, C.F., Jones, S.L. et al. Glomerular structure in type 1 (insulin dependent) diabetic patients with normo- and microalbuminuria. Kidney Int 1992, 41: 741748.

84. Remuzzi, G. \& Bertani, T. Is glomerulosclerosis a consequence of altered glomerular permeability to macromolecules. Kidney Int 1990, 38: 384-394.

85. Hansen, K.W., Christensen, C.K., Andersen, P.H., Mau Pedersen, M., Christensen, J.S. \& Mogensen, C.E. Ambulatory blood pressure in microalbuminuric type 1 diabetic patients. Kidney Int 1992, 41: 847-854.

86. Mangili, R., Bending, J.J., Scott, G., Gupta, A. \& Viberti, G. Increased sodium-lithium countertransport in red cells of patients with insulin-dependent diabetes and nephropathy. $N$ Engl J Med 1988, 318: 146-150.

87. Carr, S., Mbanya, J.C., Thomas, T. et al. Increase in glomerular filtration rate in patients with insulin-dependent diabetes and elevated erythrocyte sodium-lithium countertransport. N Engl J Med 1990, 322: 500-505.

88. Rutherford, P.A., Thomas, T.H., Carr, S.J., Taylor, R. \& Wilkinson, R. Changes in erythrocyte sodium-lithium countertransport kinetics in diabetic nephropathy. Clin Sci 1992, 82: $301-307$

89. Gall, M.A., Rossing, P., Jensen, J.S., Funder, J. \& Parving, H.H. Red cell Na${ }^{+} / \mathrm{Li}^{+}$countertransport in non-insulindependent diabetics with diabetic nephropathy. Kidney Int 1991, 39: 135-140.

90. Elving, L.D., Wetzels, J.F., de Nobel, E. \& Berden, J.H. Erythrocyte sodium-lithium countertransport is not different in type 1 (insulin-dependent) diabetic patients with and without diabetic nephropathy. Diabetologia 1991, 34: $126-128$. 
91. Zerbini, G., Laffel, L. \& Canessa, M. Elevated $V_{\max }$ and $K_{\mathrm{m}}$ for external sodium in red cell $\mathrm{Na} / \mathrm{Li}$ CTT in non-fasted insulin dependent (IDDM) patients with diabetic nephropathy. J Am Soc Nephrol 1992, 3(3): 340.

92. Zeller, K., Whittaker, E., Sullivan, L., Raskin, P. \& Jacobson, H.R. Effect of restricting dietary protein on the progression of renal failure in patients with insulindependent diabetes mellitus. $N$ Engl J Med 1991, 324: $78-84$.

93. Bjorck, S., Mulec, H., Johnsen, S.A.A., Norden, G. \& Aurell, M. Renal protective effect of enalapril in diabetic nephropathy. Br Med J 1992, 304: 339-343.

94. Lebovitz, H., Cnaan, A., Wiegman, T. et al. Enalapril slows the progression of renal disease in non-insulin dependent diabetes mellitus (NIDDM): Results of a 3-yr multicenter, randomised, prospective, double-blinded study. J Am Soc Nephrol 1992, 3(3): 335.

95. Parving, H.-H., Rossing, P., Hommel, E. \& Smidt, U.M. Renal protective effects of captopril and metoprolol in diabetic nephropathy. J Am Soc Nephrol 1992, 3(3): 337.

96. Abouna, G.M., Kremer, G.D., Daddah, S.K., Al-Adbabu, M.S., Kunar, S.A. \& Kusma, G. Reversal of diabetic nephropathy in human cadaveric kidneys after transplantation into nondiabetic recipients. Lancet 1983, ii: 1274.

97. Bilous, R., Mauer, S.M., Sutherland, D.E.R., Najarian, J.S., Goetz, F.C. \& Steffes, M.W. Effects of pancreas transplantation on the glomerular structure of renal allografts in patients with insulin-dependent diabetes. $N$ Engl J Med 1989, 321: 80-85.

98. Mau Pedersen, M., Hansen, K.W., Schmitz, A., Sorensen, K., Christensen, C.K. \& Mogensen, C.E. Effects of ACE inhibition supplementary to beta blockers and diuretics in early diabetic nephropathy. Kidney Int 1992, 41: 883-890.

99. Mogensen, C.E. Captopril delays progression to overt renal disease in insulin-dependent diabetes mellitus patients with microalbuminuria. J Am Soc Nephrol 1992, 3(3): 336.

100. Wiedman, P., Boehlen, L., De Courten, M. \& Shaw, S. Human diabetic proteinuria is affected differently by ACE inhibitors, calcium antagonists, or conventional therapy. $J$ Am Soc Nephrol 1992, 3(3): 339.

101. Gabow, P.A. Autosomal dominant polycystic kidney disease - more than a renal disease. Am J Kidney Dis 1990, 16: 403-413.

102. Gregoire, J.R., Torres, V.E., Holley, K.E. \& Farrow, G.N. Renal epithelial hyperplastic and neoplastic proliferation in autosomal dominant polycystic kidney disease. Am J Kidney Dis 1987, 9: 27-38.

103. Chapman, A.B., Rubinstein, D., Hughes, R. et al. Intracranial aneurysms in autosomal dominant polycystic kidney disease. N Engl J Med 1992, 327(13): 916-920.

104. Timio, M., Monarca, C., Pede, S., Gentili, S., Verdura, C. \& Lolli, S. The spectrum of cardiovascular abnormalities in autosomal dominant polycystic kidney disease: a 10 year follow-up in a five generation kindred. Clin Nephrol 1992, 37(5): 245-251.

105. Scheff, R.T., Zuckerman, G., Hartel, H., Delmez, J. \& Koehler, R. Diverticular disease in patients wtih chronic renal failure due to polycystic kidney disease. Ann Intern Med 1980, 92: 202-204.

106. Milutinovic, J., Fialkow, P.J., Rudd, T.G., Agoda, L.Y., Phillips, L.A. \& Bryant, J.I. Liver cysts in patients with autosomal dominant polycystic kidney disease. Am J Med 1980, 68: $741-746$.

107. Cobben, J.M., Breuning, M.H., Schoots, C., Tenkate, L.P. \& Zerres, K. Congenital hepatic fibrosis in autosomal dominant polycystic kidney disease. Kidney Int 1990, 38: 880-885.

108. Milutinovic, J., Rust, P.F., Fialkow, P.J. et al. Intrafamilial phenotypic expression of autosomal dominant polycystic kidney disease. Am J Kidney Dis 1992, 19(5): 465-472.

109. Wiebers, D.O. \& Torres, V.E. Screening for unruptured intracranial aneurysms in autosomal dominant polycystic kidney disease. $N$ Engl J Med 1992, 327(13); 953-955.
110. Gabow, P.A. \& Wilkins-Haug, L. Prediction of likelihood of polycystic kidney disease in the fetus if a parent has autosomal dominant polycystic kidney disease. In: Andreucci, V.E. \& Fine, L.G. (eds) International Year Book of Nephrology. Springer-Verlag, London, 1992, pp. 199-207.

111. Cowley, B.D., Chadwick, L.J., Grantham, J.J. \& Calvet, J.P. Elevated proto oncogene expression in polycystic kidneys of C57BL/6J (CPK) mouse. J Am Soc Nephrol 1991, I: $1048-1053$.

112. Torres, V.R., Bernot, T.J., Okamura, M. et al. Mechanisms affecting the development of renal cystic disease induced by diphenyl thiazole. Kidney Int 1988, 33: 1130-1139.

113. Gabow, P.A. Polycystic kidney disease: clues to pathogenesis. Kidney Int 1991, 40: 989-996.

114. Watson, M.L., Macnicol, A.M., Allan, P.L. \& Wright, A.F Effects of angiotensin converting enzyme inhibition in adult polycystic kidney disease. Kidney Int 1992, 41: 206-210.

115. Harrap, S.B., Davies, D.L., MacNicol, A.M. et al. Renal cardiovascular and hormonal characteristics of young adults with autosomal dominant polycystic kidney disease. Kidney Int 1991, 40: 501-508.

116. Elzinga, L.W., Barry, J.M., Torres, V.E. et al. Cyst decompression surgery for autosomal dominant polycystic kidney disease. J Am Soc Nephrol 1992, 2: 1219-1226.

117. Scoble, J.E., Maher, E.R., Hamilton, G., Dick, R., Sweny, P. \& Moorhead, J.F. Atherosclerotic renovascular disease causing renal impairment - a case for treatment. Clin Nephrol 1989, 31(3): 119-122.

118. Harding, M.B., Smith, L.R., Himmerstein, S.I. et al. Renal artery stenosis: prevelance and associated risk factors in patients undergoing routine cardiac catheterization. $J \mathrm{Am}$ Soc Nephrol 1992, 2: 1608-1616.

119. Choudri, A.H., Claland, J.G.F., Rowlands, P.C. et al. Unsuspected renal artery stenosis in peripheral vascula disease. $\mathrm{Br}$ Med J 1990, 301: 1197-1198.

120. Brown, E.A., Braun, M., Cassar, J., Wise, P., Barratt, Renal artery stenosis: an important finding in diabetic rene disease. Nephrol Dial and Transplant 1992, 17: 684.

121. Dahlof, B., Lindholm, L.H., Hanson, L. et al. Morbidity and mortality in the Swedish trial in old patients with hypertension (STOP-hypertension). Lancet 1991, 338 $1281-1285$

122. Shep Cooperative Research Group. Prevention of stroke by anti-hypertensive drug therapy in older persons with isolated systolic hypertension. JAMA 1991, 265: 32553264.

123. Pickering, T.G., Herman, L., Devereux, R.B. et al. Recurrent pulmonary oedema in hypertension due to bilateral renal artery stenosis: treatment by angioplasty or surgica revascularization. Lancet 1988 , ii, 551-552.

124. Kalra, P.A., Mamtora, H., Holmes, A.M. \& Waldek, S. Renovascular disease and renal complications of angiotensin converting enzyme inhibitor therapy. $Q J \mathrm{Med} 1990$ 77(282): $1013-1018$.

125. McLean, A.G., Hilson, A.J.W., Scoble, J.E. et al. Screening for renovascular disease with captopril-enhanced renography. Nephrol Dial Transplant 1992, 7: 211-215.

126. Editorial. Cholesterol embolism. Lancet 1991, 338: 1365 1366.

127. Novick, A.C., Khauli, R.B. \& Vidt, D.G. Diminished operative risk and improved results following revascularisation for atherosclerotic renovascular disease. Urol Clin $N$ Am 1984, 11(3): 435-449.

128. Wollenwebber, J., Sheps, S.G. \& Davis, G.P. Clinical course of atherosclerotic renovascular disease. Am J Cardiol 1968, 21: $60-71$.

129. Novick, A.C. Management of renovascular disease. Circulation 1991, 83(S1): 1-171. 
130. Rees, C.R., Palmaz, J.C., Becker, G.J. et al. Palmaz stent in atherosclerotic stenoses involving the ostia of the renal arteries: preliminary report of a multicentre study. Radiol 1991, 181: 507-514.

131. Kuhn, F.-P., Kutkuhn, B., Torsello, G. \& Modder, V. Renal artery stenosis: preliminary results of treatment with the Strecker stent. Radiol 1991, 180: 367-372.

132. Hahmann, H.W., Bunte, T., Hellwig, N. et al. Progression and regression of minor coronary arterial narrowing by quantitative angiography after fenofibrate therapy. $A m J$ Cardiol 1991, 67: 957-961.

133. Blankenhorn, D.H., Nessim, S.A., Johnson, R.L., Sanmarco, M.E., Azan, S.P. \& Cashin-Hemphill, L. Beneficial effects of combined colestipol-niacin therapy on coronary atherosclerosis and coronary venous by-pass grafts. $J$ Am Med Assoc 1987, 257: 3233-3240.

134. Armstrong, M.L., Heistad, D.D. \& Lopez, J.A.G. Regression of atherosclerosis: a role for calcium antagonists. $\mathrm{Am} \mathrm{J}$ Hypertension 1991, 4: 5035-5115.

135. Lin, F.-K., Suggs, S., Lin, C.H. et al. Cloning and expression of the human erythropoietin gene. Proc Natl Acad Sci 1985, 92: 7580-7585.

136. Jacobs, K., Shoemaker, C., Rudersdorf, R. et al. Isolation and characterisation of genomic and cDNA clones of human erythropoietin. Nature 1985, 313: 806-810.

137. Winnearls, C., Oliver, D., Pippard, M. et al. Effect of human erythropoietin derived from recombinant DNA on the anaemia of patients maintained by chronic haemodialysis. Lancet 1986, 2: 1175-1178.

138. Eschbach, J.W., Egrie, J., Downing, M. et al. Correction of anemia of end-stage renal disease with recombinant human erythropoietin. $N$ Engl J Med 1987, 316: 73-78.

139. Goldwasser, E. From protein to gene to protein: the molecular biology of erythropoietin. Am J Kidney Dis 1991, 4(Suppl 1): 10-13.

140. Lacombe, C., Da Silva, J.-L., Bruneval, P. et al. Erythropoietin: sites of synthesis and regulation of secretion. Am J Kidney Dis 1991, 4(Suppl 1): 14-19.

141. Koury, M.J. \& Bondurant, M.C. Mechanism of erythropoietin action. Am J Kidney Dis 1991, 4(Suppl 1): 20-23.

142. Salmonson, T., Danielson, B.G., Grahnen, A. \& Wikstrom, B. Pharmacokinetics of intravenous recombinant human erythropoietin in patients with chronic renal failure. J Intern Med 1990, 228: 53-57.

143. Cotes, P.M., Pippard, M.J., Reid, C.D. et al. Characterization of the anaemia of chronic renal failure and the mode of its correction by a preparation of human erythropoietin (r-HuEPO). An investigation of the pharmacokinetics of intravenous erythropoietin and its effects on erythrokinetics. $Q J$ Med 1989, 70: 113-137.

144. Nielsen, O.J. Pharmacokinetics of recombinant human erythropoietin in chronic haemodialysis patients. Pharmacol Toxicol 1990, 66: 83-86.

145. Besarab, A., Flaharty, K.K., Erslev, A.J. et al. Clinical pharmacology and economics of recombinant human erythropoietin in end-stage renal disease: the case for subcutaneous administration. J Am Soc Nephrol 1992, 2: $1405-1416$.

146. Kindler, J., Eckardt, K.U., Ehmer, B. et al. Single-dose pharmacokinetics of recombinant human erythropoietin in patients with various degrees of renal failure. Nephrol Dial Transplant 1989, 4: 345-349.

147. Nissenson, A.R., National cooperative rHu erythropoietin study in patients with chronic renal failure: a phase IV multicenter study. Report of National Cooperative rHu Erythropoietin Study Group. Am J Kidney Dis 1991, 18: 24-33.

148. McMahon, L.P. \& Dawborn, J.K. Experience with low dose intravenous and subcutaneous administration of recombinant human erythropoietin. Am J Nephrol 1990, 10: 404-408.
149. Granolleras, C., Branger, B., Deschodt, G. et al. Two years experience of daily self-administered subcutaneous erythropoietin. Blood Purif 1990, 8: 268-271.

150. Horl, W.H. Optimal route of administration of erythropoietin in chronic renal failure patients: intravenous versus subcutaneous. Acta Haematol 1992, 87(Suppl 1): $16-19$.

151. Garred, L.J. \& Pretlac, R. Mathematical modeling of erythropoietin therapy. ASAIO Trans 1991, 37: M457M459.

152. Besarab, A., Besarab, F.M. \& Miller, D. Effects of dialysis factors and route of administration on response of hemodialysis patients to recombinant human erythropoietin. ASAIO Trans 1991, 37: M181-M182.

153. Stevens, J.M., Auer, J., Strong, C.A. et al. Stepwise correction of anaemia by subcutaneous administration of human recombinant erythropoietin in patient with chronic renal failure maintained by continuous ambulatory peritoneal dialysis. Nephrol Dial Transplant 1991, 6: 487-494.

154. Piraino, B. \& Johnston, J.R. The use of subcutaneous erythropoietin in CAPD patients. Clin Nephrol 1990, 33: 200-202.

155. Nissenson, A.R., Swartz, R., Zimmerman, S.W. et al. A double blind placebo controlled study of recombinant human erythropoietin in peritoneal dialysis patients. $J \mathbf{A m}$ Soc Nephrol 1990, 1: 405(abstract).

156. Lui, S.F., Chung, W.W., Leung, C.B., Chan, K. \& Lai, K.N. Pharmacokinetics and pharmacodynamics of subcutaneous and intraperitoneal administration of recombinant human erythropoietin in patients on continuous ambulatory peritoneal dialysis. Clin Nephrol 1990, 33: 47-51.

157. MacDougall, I.C., Roberts, D.E., Robinson, M.I. et al. Pharmacokinetics of recombinant human erythropoietin in patients on continuous peritoneal dialysis. Lancet 1989, 1: $425-427$

158. Lui, S.F., Law, C.B., Ting, S.M., Li, P. \& Lai, K.N. Once weekly versus twice weekly subcutaneous administration of recombinant human erythropoietin in patients on continuous ambulatory peritoneal dialysis. Clin Nephrol 1991, 36: $246-251$

159. Hood, V.L. \& Ingraham, A. Erythropoietin for chronic ambulatory peritoneal dialysis patients: once a week can be enough. J Am Soc Nephrol 1992, 2: 1545-1546.

160. Besarab, A. \& Golper, T.A. Response of continuous peritoneal dialysis patients to subcutaneous recombinant human erythropoietin differs from that of hemodialysis patients. ASAIO Trans 1991, 37: M395-M396.

161. Watson, A.J., Gimenez, L.F., Cotton, S., Walser, M. \& Spivak, J.L. Treatment of the anemia of chronic renal failure with subcutaneous recombinant human erythropoietin. $\mathrm{Am}$ J Med 1990, 89: 432-435.

162. Abraham, P.A., Opsahl, J.A., Rachael, K.M., Asinger, R. \& Halstenson, C.E. Renal function during erythropoietin therapy for anemia in predialysis chronic renal failure patients. Am J Nephrol 1990, 10: 128-136.

163. Frenken, L.A., Verberckmoes, R., Michielsen, P. \& Koene, R.A. Efficacy and tolerance of treatment with recombinanthuman erythropoietin in chronic renal failure (pre-dialysis) patients. Nephrol Dial Transplant 1989, 4: 782-786.

164. Kleinman, K.S., Schweitzer, S.U., Perdue, S.T. et al. The use of recombinant human erythropoietin in the correction of anemia in predialysis patients and its effect on renal function: a double-blind, placebo-controlled trial. $\mathrm{Am} \mathrm{J}$ Kidney Dis 1989, 14: 486-495

165. Eschbach, J.W., Kelly, M.R., Haley, N.R., Abels, R.I. \& Adamson, J.W. Treatment of the anemia of progressive renal failure with recombinant human erythropoietin. $N$ Engl J Med 1989, 321: 158-163.

166. Lim, V.S. Recombinant erythropoietin in predialysis patients. Am J Kidney Dis 1991, 18(4)(Suppl 1): 34-37. 
167. Lai, K.N., Wong, K.C., Li, P.K. \& Lui, S.F. Use of recombinant erythropoietin in thalassemic patients on dialysis. Am J Kidney 1992, 19: 239-245.

168. Holley, J.L., Nolan, T.A. \& Piraino, B. Recombinant human erythropoietin in a patient with multiple myeloma and end-stage renal disease. Clin Nephrol 1992, 37: 145- 147.

169. Taylor, J., Mactier, R.A., Stewart, W.K. \& Henderson, I.S. Effect of erythropoietin on anaemia in patients with myeloma receiving haemodialysis. $\mathrm{Br}$ Med J 1990, 301: 476-477.

170. Huraib, S., Al Momen, A.K., Gader, A.M., Mitwalli, A., Sulimani, F. \& Abu Aisha, H. Effect of recombinant human erythropoietin (rHuEpo) on the hemostatic system in chronic hemodialysis patients. Clin Nephrol 1991, 36: 252-257.

171. Taylor, J.E., Henderson, I.S., Stewart, W.K. \& Belch, J.J. Erythropoietin and spontaneous platelet aggregation in haemodialysis patients. Lancet 1991, 338: 1361-1362.

172. Vigano, G., Benigni, A., Mendogni, D., Mingardi, G., Mecca, G. \& Remuzzi, G. Recombinant human erythropoietin to correct uremic bleeding. Am J Kidney Dis 1991 , 18: 44-49.

173. Evans, R.W., Rader, B. \& Manninen, D.L. The quality of life of hemodialysis recipients treated with recombinant human erythropoietin. Cooperative Multicenter EPO Clinical Trial Group. JAMA 1990, 263: 825-830.

174. Deniston, O.L., Luscombe, F.A., Buesching, D.P., Richner, R.E. \& Spinowitz, B.S. Effect of long-term epoetin beta therapy on the quality of life of hemodialysis patients. ASAIO Trans 1990, 36: M157-M160.

175. Auer, J., Simon, G., Stevens, J. et al. Quality of life improvements in CAPD patients treated with subcutaneously administered erythropoietin for anemia. Perit Dial Int 1992, 12: 40-42.

176. Levin, N.W. Quality of life and hematocrit level. Am J Kidney Dis 1992, 20: 16-20.

177. Canadian Erythropoietin Study Group. Assocation between recombinant human erythropoietin and quality of life and exercise capacity of patients receiving haemodialysis. $\mathrm{Br}$ Med J 1990, 300: 573-578.

178. Silberberg, J., Racine, N., Barre, P. \& Sniderman, A.D. Regression of left ventricular hypertrophy in dialysis patients following correction of anemia with recombinant human erythropoietin. Can J Cardiol 1990, 6: 1-4.

179. Goldberg, N., Lundin, A.P., Delano, B., Friedman, E.A. \& Stein, R.A. Changes in left ventricular size, wall thickness, and function in anemic patients treated with recombinant human erythropoietin. Am Heart $J$ 1992, 124: 424-427.

180. Macdougall, I.C., Cavill, I., Hulme, B. et al. Detection of functional iron deficiency during Epo therapy. A new approach. J Am Soc Nephrol 1990, 1: 402.

181. Macdougall, I.C., Lewis, N.P., Saunders, M.J. et al. Longterm cardiorespiratory effects of amelioration of renal anaemia by erythropoietin. Lancet 1990, 335: 489-493.

182. Raine, A.E. \& Roger, S.D. Effects of erythropoietin on blood pressure. Am J Kidney Dis 1991, 18: 76-83.

183. Hori, K., Onoyama, K., Iseki, K., Fujimi, S. \& Fujishima, $M$. Hemodynamic and volume changes by recombinant human erythropoietin (rHuEPO) in the treatment of anemic hemodialysis patients. Clin Nephrol 1990, 33: 293-298.

184. Buckner, F.F., Eschbach, J.W., Haley, N.R. et al. Correction of the anaemia in haemodialysis patients with recombinant human erythropoietin: haemodynamic changes and risks for hypertension. Kidney Int 1989, 35: 190.

185. London, G.M., Zins, B., Pannier, B. et al. Vascular changes in hemodialysis patients in response to recombinant human erythropoietin. Kidney Int 1989, 36: 878-882.

186. Linde, T.G., Sandhagen, B., Danielson, B.G. \& Wikstrom B. Impaired erythrocyte fluidity during treatment of renal anaemia with erythropoietin. J Intern Med 1992, 231: $601-606$.
187. Brown, C.D. \& Friedman, E.A. Clinical and blood rheologic stability in erythropoietin-treated predialysis patients. $\mathrm{Am} \mathrm{J}$ Neprhol 1990, 10(Suppl 2): 29-33.

188. Creutzig, A., Caspary, L., Nonnast Daniel, B. et al. Skin microcirculation and regional peripheral resistance in $\triangle$ patients with chronic renal anaemia treated with recombinant human erythropoietin. Eur J Clin Invest 1990, 20: 219-223.

189. Fritschka, E., Neumayer, H.H., Seddighi, S., Thiede, H.M., Distler, A. \& Philipp, T. Effect of erythropoietin on parameters of sympathetic nervous activity in patients undergoing chronic haemodialysis. Br J Clin Pharmacol 1990, 30(Suppl 1): 135S-138S.

190. Muller, R., Steffen, H.M., Brunner, R. et al. Changes in the alpha adrenergic system and increase in blood pressure with recombinant human erythropoietin (rHuEpo) therapy for renal aanemia. Clin Invest Med 1991, 14: 614-622.

191. Bennett, W.M. A multicentre clinical trial of epoietin beta for anemia of end stage renal disease. J Am Soc Nephrol 1991, 1: 990-998.

192. Edmunds, M.E., Wallis, J., Tucker, B. et al. Seizures in haemodialysis patients treated with recombinant human $\exists$ erythropoietin. Nephrol. Dial Transplant 1989, 4: 10651069.

193. Strandgaard, S., Oleson, J., Skinhoj, E. et al. Autoregulation of the brain circulation in severe arterial hypertension. $\mathrm{Br}$ Med J 1973, 1: 507-510.

194. Hirakata, H., Yao, H., Osato, S. et al. CBF and oxygen metabolism in hemodialysis patients: effects of anemia correction with recombinant human EPO. Am J Physiol 1992, 262: F737-F743

195. Johnson, W.J., McCarthy, J.T., Yanagihara, T. et al. Effects of recombinant human erythropoietin on cerebral and cutaneous blood flow and on blood coagulability. Kidney Int 1990, 38: 919-924.

196. Bennett, W.M. Side effects of erythropoietin therapy. $A m$ Kidney Dis 1991, 18 (4 Suppl 1): 84-86.

197. Van Wyck, D.B. Impact of erythropoietin on dialysto prescription. Am J Kidney Dis 1991, 18 (4 Suppl 1): 71-75.

198. Lim, V.S., Flanigan, M.J. \& Fangman, J. Effect of hematocrit on solute removal during high efficiency hemodialysis. Kidney Int 1990, 37: 1557-1562.

199. Hutchison, A.J., Ofsthun, N.J., Howarth, D. \& Gokal, R. The effect of hemoglobin concentration on peritoneal mass transfer and drain volumes in continuous ambulatory peritoneal dialysis. Perit Dial Int 1992, 12: 230-233.

200. Taylor, J.E., Mactier, R.A., Henderson, I.S., Belch, J.J. \& Stewart, W.K. Dialysis efficiency in continuous ambulatory peritoneal dialysis patients treated with erythropoietin. Perit Dial Int 1992, 12: 221-226.

201. Korbet, S.M., Vonesh, E.F. \& Firanek, C.A. The effect of hematocrit on peritoneal transport. Am J Kidney Dis 1991, 18: $573-578$.

202. Steinhauer, H.B., Lubrich-Birkner, I., Dreyling, K.W. et al. Increased ultrafiltration after erythropoietin-induced correction of renal anaemia in patients on continuous ambulatory peritoneal dialysis. Nephron 1989, 53: 91-92.

203. Kooistra, M.P., van Es, A., Struyvenberg, A. \& Marx, J.J. Iron metabolism in patients with the anaemia of end-stage renal disease during treatment with recombinant human $N$ erythropoietin. Br J Haematol 1991, 79: 634-639.

204. Jones Lecointe, A., Green, P.J. \& Lee, H.A. Sub-optimal N doses of human recombinant erythropoietin markedly lower $\mathrm{N}$ serum ferritin. Clin Lab Haematol 1991, 13: 251-253.

205. Drueke, T.B. Modulating factors in the hematopoietic response to erythropoietin. Am J Kidney Dis 1991, 18: $87-92$.

206. Stivelman, J.C. Resistance to recombinant human erythropoietin: a real clinical entity? Semin Nephrol 1989, 9: 8-11 
207. Clibon, U., Bonewald, L., Caro, J. et al. Erythropoietin fails to reverse the anaemia in mice continuously exposed to tumor necrosis factor-alpha in vivo. Exp Haematol 1990, 18: 438-441.

208. Schooley, J.C., Kullgren, B. \& Allison, A.C. Inhibition by interleukin-1 of the action of erythropoietin on erythroid precursors and its possible role in the pathogenesis of hypoplastic anemias. Br J Haematol 1987, 67: 11-17.

209. Klassen, D.K. \& Spivac, J.L. Hepatitis related hepatic erythropoietin production. Am J Med 1990, 89: 684-686.

210. Silver, J., Russell, J. \& Sherwood, L.M. Regulation by vitamin D metabolites of messenger ribonucleic acid for pre-pro parathyroid hormone in isolated bovine parathyroid cells. Proc Natl Acad Sci USA 1985, 82: 4270-4273.

211. Korkor, A.B. Reduced binding of $[3 \mathrm{H}] 1,25-(\mathrm{OH})_{2} \mathrm{D} 3$ in parathyroid glands of patients with renal failure. $N$ Engl $J$ Med 1987, 316: 1573-1577.

212. Brown, A.J., Dusso, A., Lopez Hilker, S., Lewis Finch, J., Grooms, P. \& Slatopolsky, E. 1,25- $(\mathrm{OH})_{2}$ D receptors are decreased in parathyroid glands from chronically uremic dogs. Kidney Int 1989, 35: 19-23.

213. Hsu, C.H., Patel, S. \& Vanholder, R. The mechanism of decreased calcitriol receptor concentration in renal failure. $J$ Am Soc Nephrol 1992, 3(3): 696.

214. Fukagawa, M., Kaname, S., Igarashi, T., Ogata, E. \& Kurokawa, K. Regulation of parathyroid hormone synthesis in chronic renal failure in rats. Kidney Int 1991, 39: $874-881$

215. Navey-Many, T., Marks, R., Keshet, E., Pike, J.W. \& Silver, J. Regulation of 1,25-dihydroxyvitamin D3 receptor gene by 1,25-dihydroxyvitamin D3 in the parathyroid in vivo. J Clin Invest 1990, 86: 1968-1975.

216. Delmez, A.J., Tindira, C., Grooms, P., Dusso, A., Windus, D.W. \& Slatopolsky, E. Parathyroid hormone suppression by intravenous 1,25 dihydroxyvitamin $\mathrm{D}$. A role for increased sensitivity to calcium. J Clin Invest 1989, 83: $1349-1355$.

217. Dunlay, R., Rodriguez, M., Felsenfeld, A.J. \& Llach, F. Direct inhibitory effect of calcitriol on parathyroid function (sigmoidal curve) in dialysis. Kidney Int 1989, 36: $1093-1098$

218. Rodriguez, M., Felsenfeld, A.J., Torres, A., Pederson, L. \& Llach, F. Calcitonin, an important factor in the calcemic response to parathyroid hormone in the rat. Kidney Int 1991 , 40: 219-225.

219. Bover, J., Trinidad, R., Felsenfeld, A., Rodriguez, M. \& Llach, F. The effect of azotaemia and the magnitude of hyperparathyroidism on the calcaemic response to parathyroid hormone. J Am Soc Nephrol 1992, 3(3): 692.

220. Rodriguez, M., Martin Malo, A., Martinez, M.E., Torres, A., Felsenfeld, A.J. \& Llach, F. Calcemic response to parathyroid hormone in renal failure: role of phosphorus and its effect on calcitriol. Kidney Int 1991, 40: 1055-1062.

221. Lopez-Hilker, S., Dusso, A., Rapp, N., Martin, K.J. \& Slatopolsky, E. Phosphorus restriction reverses hyperparathyroidism in uremia independent of changes in calcium and calcitriol. Am J Physiol 1990, 28: F432-F437.

222. Delmez, J.A. \& Slatopolsky, E. Hyperphosphatemia: its consequences and treatment in patients with chronic renal disease. Am J Kidney Dis 1992, 19: 303-317.

223. Wilske, J., Bjorck, S. \& Delin, K. Serum concentrations of calcitriol and PTH in hemo-dialysis patients on treatment with calcium carbonate. Scand J Urol Nephrol 1992, 26: $51-54$

224. Meric, F., Yap, P. \& Bia, M.J. Etiology of hypercalcemia in hemodialysis patients on calcium carbonate therapy. $\mathrm{Am} \mathrm{J}$ Kidney Dis 1990, 16: 459-464.

225. Sheikh, M.S., Maguire, J.A., Emmett, K. et al. Reduction of dietary phosphorus absorption by phosphorus binders. A theoretical, in vitro, and in vivo study. $J$ Clin Invest 1989, 83: $66-73$.
226. Mai, M.L., Emmett, M., Sheikh, M.S., Santa Ana, C.A., Schiller, L. \& Fordtran, J.S. Calcium acetate, an effective phosphorus binder in patients with renal failure. Kidney Int 1989, 36: 690-695.

227. Moriniere, Ph., Djeras, M., Boudaillez, B. et al. Control of predialysis hyperphosphataemia by oral calcium acetate and calcium carbonate. Nephron 1992, 60: 6-11.

228. Sawyer, N., Noonan, K., Altman, P., Marsh, F. \& Cunningham, J. High dose calcium carbonate with stepwise reduction in dialysate calcium concentration: the effect on phosphate control and aluminium avoidance in haemodialysis patients. Nephrol Dial Transplant 1989, 4: 105-109.

229. Piraino, B., Bernardini, J., Holley, J., Johnson, J.R., Perlmutter, J.A. \& Martes, L. Calcium mass transfer in peritoneal dialysis using $2.5 \mathrm{mEq} / 1$ calcium dialysate. Clin Nephrol 1992, 37: 48-51.

230. Andress, D.L., Norris, K.C., Coburn, J.W., Slatopolsky, E.A. \& Sherrard, D.J. Intravenous calcitriol in the treatment of refractory osteitis fibrosa of chronic renal failure. $N$ Engl J Med 1989, 321: 274-279.

231. Reichel, H., Szabo, A., Pesian, S. et al. Intermittent versus continuous administration of $1,25(\mathrm{OH})_{2} \mathrm{D} 3$. Comparison of efficiency. J Am Soc Nephrol 1992, 3(3): 699.

232. Rodriguez, A.P., Lorenzo, V., Concepcion, M.T. et al. The effect of long-term calcitriol administration after haemodialysis on parathyroid function. $J$ Am Soc Nephrol 1992, 3(3): 700 .

233. Kwan, J.T.C., Almond, M.K., Beer, J. \& Cunningham, J. Evidence for tolerance to pulsed oral calcitriol in haemodialysis patients. J Am Soc Nephrol 1992, 3(3): 697.

234. Varghese, Z., Moorhead, J.F. \& Farrington, K. Effect of 24,25-dihydroxycholecalciferol on intestinal absorption of calcium and phosphate and on parathyroid hormone secretion in chronic renal failure. Nephron 1992, 60: 286-291.

235. Slatopolsky, E., Berkoben, M., Kelber, J., Brown, A. \& Delmez, J. Effects of calcitriol and non-calcaemic vitamin D analogues on secondary hyperparathyroidism. Kidney Int 1992, 42 (Suppl. 38): S43-S49.

236. Moriniere, P., Cohen-Solal, M., Belbrick, S. et al. Disappearance of aluminic bone disease in long term asymptomatic dialysis population restricting $\mathrm{Al}(\mathrm{OH})_{3}$ intake: Emergence of an idiopathic adynamic bone disease not related to aluminium. Nephron 1989, 53: 93-101.

237. Malluche, H.H. \& Monier-Faugere, M.-C. Risk of adynamic bone disease in dialysed patients. Kidney Int 1992, 42(Suppl. 38): S62-S67.

238. Cohen Solal, M.E., Sebert, J.L., Boudailliez, B. et al. Non-aluminic adynamic bone disease in non-dialyzed uremic patients: a new type of osteopathy due to overtreatment? Bone 1992, 13: 1-5.

239. Vanholder, R.C. \& Ringoir, S.M. Adequacy of dialysis: A critical analysis. Kidney Int 1992, 42: 540-558.

240. Babb, A.L., Popovich, R.P., Christopher, T.G. \& Scribner, B.H. The genesis of the square metre-hour hypothesis. Trans Am Soc Artif Intern Organs 1971, 17: 81-91.

241. Held, P.J., Blagg, C.R., Liska, D.W., Port, P.K., Hakim, R. \& Levin, N. The dose of hemodialysis according to dialysis prescription in Europe and the United States. Kidney Int 1992, 42(Suppl 38): S16- S21.

242. Held, P.J., Levin, N.W., Bovbjerg, R.R., Pauly, M.V. \& Diamond, L.H. Mortality and duration of hemodialysis treatment. JAMA 1991, 265: 871-875.

243. Raja, R., Kramer, M. \& Rosenbaum, J. Long-term hemodialysis-implications of the Dialysis Index. Trans Am Soc Artif Intern Organs 1978, 24: 367-373.

244. Buur, T., Timpka, T. \& Lundberg, M. Urea kinetics and clinical evaluation of the haemodialysis patient. Nephrol Dial Transplant 1990, 5: 347-351. 
245. Degoulet, P., Legrain, M., Reach, I. et al. Mortality risks in patients treated by chronic hemodialysis. Nephron 1982, 31: $103-110$.

246. Lowrie, E.G. \& Lew, N.L. Death risk in haemodialysis patients: the predictive value of commonly measured variables and an evaluation of death rate differences between facilities. Am J Kidney Dis 1990, 15: 458-482.

247. Lowrie, E.G., Lew, N.L. \& Huang, W.H. Race and diabetes as death predictors in haemodialysis patients. Kidney Int 1992, 42(Suppl. 38): S22-S31.

248. Haider, M. \& Haider, S.Q. Assessment of protein calorie malnutrition. Clin Chem 1984, 30: 1286-1299.

249. Phillips, A., Shaper, G. \& Whincup, P.H. Association between serum albumin and mortality from cardiovascular disease, cancer, and other causes. Lancet 1989, 2: 1434-1436.

250. Sargent, J.A. \& Lowrie, E.G. Which mathematical model to study uremic toxicity? National Cooperative Dialysis Study. Clin Nephrol 1992, 17(6): 303-314.

251. Laird, N.M., Berkey, C.S. \& Lowrie, E.G. Modeling success or failure of dialysis therapy: The National Cooperative Dialysis Study. Kidney Int 1983, 23 (Suppl. 13): S101-S106.

252. Gotch, F.A. \& Sargent, J.A. A mechanistic analysis of the National Cooperative Dialysis Study (NCDS). Kidney Int 1985, 28: 526-534.

253. Lindsay, R.M. \& Spanner, E. A hypothesis: The protein catabolic rate is dependent on the type and amount of treatment in dialysed uremic patients. Am J Kidney Dis 1989, 13: $382-389$.

254. Lindsay, R.M., Spanner, E., Heidenheim, P. et al. Which comes first, Kt/V or PCR - chicken or egg? Kidney Int 1992, 42(Suppl 38): S32-S36.

255. Flanigan, M.J., Fangman, J. \& Lim, V.S. Quantitating hemodialysis: a comparison of three kinetic models. Am J Kidney Dis 1991, 17: 295-302.

256. Ijelu, G., Corona, M. \& Raja, R.M. Various methods for calculation of $\mathrm{Kt} / \mathrm{V}$ : a clinical comparison. ASAIO Trans 1990, 36: M364-M366.

257. Basile, C., Casino, F. \& Lopez, T. Percent reduction in blood urea concentration during dialysis estimates $\mathrm{Kt} / \mathrm{V}$ in a simple and accurate way. Am J Kidney Dis 1990, 15: 40-45.

258. Keshaviah, P.R. \& Collins, A.J. A reappraisal of the National Dialysis Cooperative Study (NCDS) (Abstract). Kidney Int 1988, 33: 227.

259. Charra, B., Calemard, E., Ruffet, M. et al. Survival as an index of adequacy of dialysis. Kidney Int 1992, 41: 1286-1291.

260. Collins, A.J. \& Keshaviah, P.R. Are there limitations to shortening dialysis treatment? ASAIO Trans 1988, 34: 1-5.

261. Pedrini, L.A., Zereik, S. \& Rasmy, S. Causes, kinetics, and clinical implications of post-haemodialysis urea rebound. Kidney Int 1988, 34: 817-821.

262. Tattersall, J., Farrington, K., Aldridge, C. \& Greenwood, R.N. Underdialysis caused by reliance on single-pool urea kinetic modelling. J Am Soc Nephrol 1992, 3(3): 398.

263. Blake, P.G., Sombolos, K., Abraham, G. et al. Lack of correlation between urea kinetic indices and clinical outcomes in CAPD patients. Kidney Int 1991, 39: 700-706.

264. Lamiere, N.H., Vanholder, R., Veyt, D., Lambert, M.-C. \& Ringoir, S. A longitudinal, five year survey of urea kinetic parameters in CAPD patients. Kidney Int 1992, 42: $426-432$.

265. Tattersall, J.E., Doyle, S., Greenwood, R.N. \& Farrington, $\mathrm{K}$. Urea kinetic modelling and underdialysis in CAPD patients. J Am Soc Nephrol 1992, 3(3): 420.

266. Teehan, B.P., Schleifer, C.R., Brown, J.M., Sigler, C.R. \& Raimondo, J. Urea kinetic analysis and clinical outcome on CAPD. A 5 year longitudinal study. Adv Perit Dial 1990, 6: $181-185$.
267. Keshaviah, P.R., Nolph, K.D. \& Van Stone, J.C. The peak concentration hypothesis: a urea kinetic approach to comparing the adequacy of continuous ambulatory peritoneal dialysis (CAPD) and hemodialysis. Perit Dial Int 1989, 9: $257-260$.

268. Cheigh, J.S., Melite, C., Sullivan, J.F., Rubin, A.L. \& Stenzel, K.H. Hypertension is not adequately controlled in hemodialysis patients. Am J Kidney Dis 1992, 19: 453-459.

269. Huting, J. \& Schutterle, G. Cardiovascular factors influencing survival in end-stage renal disease treated by continuous ambulatory peritoneal dialysis. Am J Cardiol 1992, 69: 123-127.

270. Charra, B., Calemard, E., Uzan, M., Terrat, J.C., Vannel, T. \& Laurent, G. Carpal-tunnel syndrome, shoulder pain and amyloid deposits in long-term hemodialysis patients. Proc Eur Dial Transplant Assoc 1984, 21: 291-295.

271. Gejyo, F., Yamada, T., Odani, S. et al. A new form of amyloid protein associated with chronic hemodialysis was identified as B2-microglobulin. Biochem Biophys Res Comm 1985, 129: 701-706.

272. Brown, E., Soldano, L. \& Hendler, E. Dialysis-related amyloidosis during peritoneal dialysis. ASAIO Trans 1990, 36: $17-20$.

273. Bindi, P. \& Chanard, J. Destructive spondyloarthropathy in dialysis patients: an overview. Nephron 1990, 129: 701-706.

274. Kuntz, D., Naveau, B., Bardin, T., Drueke, T., Treves, R. \& Dryll, A. Destructive spondyloarthropathy in dialysis patients. A new syndrome. Arthritis Rheum 1984, 27: 369-375.

275. Charra, B., Calemard, E. \& Laurent, G. Chronic renal failure treatment duration and mode: their relevance to the late dialysis periarticular syndrome. Blood Purif 1988, 6: $117-124$.

276. Van Ypersele de Strihou, C., Honhon, B., Vandenbrouke J.M., Huaux, J.P., Noel, H. \& Maldague, B. Dialysiø amyloidosis. Adv Nephrol 1988, 17: 401-422.

277. van Ypersele de Strihou, C., Jadoul, M., Malghem, J Maldague, B. \& Jamart, J. Effect of dialysis membrane and patient's age on signs of dialysis-related amyloidosis. The Working Party on Dialysis Amyloidosis. Kidney Int 1991, 39: $1012-1019$.

278. Maher, E.R., Hamilton Dutoit, S., Baillod, R.A., Sweny, P. \& Moorhead, J.F. Gastrointestinal complications of dialysis related amyloidosis. $\mathrm{Br} \mathrm{Med} J$ 1988, 297: 265-266.

279. Herbelin, A., Thu Nguyen, A., Zingraff, J., Urena, P. \& Descamps-Latscha, B. Influence of uraemia and hemodialysis on circulating interleukin-1 and tumor necrosis factor. Kidney Int 1990, 37: 116-125.

280. Thu Nguyen, A., Lethias, C., Zingraff, J., Herbelin, A., Naret, C. \& Descamps-Latscha, B. Hemodialysis membrane induced activation of phagocyte oxidative metabolism detected in vivo and in vitro within microamounts of whole blood. Kidney Int 1985, 28: 158-167.

281. Hakim, R.M., Breillat, J., Lazarus, J.M. \& Port, F.K. Complement activation and hypersensitivity reactions to dialysis membranes. $N$ Engl J Med 1984, 311: 878-882.

282. Zaoui, P.M., Stone, W.J. \& Hakim, R.M. Effects of dialysis membranes on beta 2-microglobulin production and cellular expression. Kidney Int 1990, 38: 962-968.

283. Floege, J., Granolleras, C., Merscher, S. et al. Is the rise in plasma beta-2-microglobulin seen during hemodialysis meaningful? Nephron 1989, 51: 6-12.

284. Bommer, J., Seelig, P., Seelig, R. et al. Determinants of Beta 2-microglobulin concentration: possible relation to membrane biocompatibility. Nephrol Dial Transplant 1987, 2: $22-25$. 
285. Honig, R., Marsen, T., Schad, S., Barth, C., Pollok, M. \& Baldamus, C. Correlation of Beta-2-microglobulin concentration changes to distribution volume. Int $J$ Artif Organs 1988, 11: 459-464.

286. Chanard, J., Toupance, O., Lavaud, S., Jaisser, F. \& Gillery, P. Serum beta 2 microglobulin and extracellular fluid volume during haemodialysis. Nephrol Dial Transplant 1989, 4: 549-554.

287. Bingel, M., Lonnemann, G., Koch, K.M. \& Shaldon, S. Enhancement of in vitro human interleukin-1 production by sodium acetate. Lancet 1987, 1: 14-16.

288. Lonnemann, G., Bingel, M., Floege, J., Koch, K.M., Shaldon, S. \& Dinarello, C.A. Detection of endotoxin-like interleukin-1 induction during in vitro dialysis. Kidney Int 1988, 33: 29-35.

289. Martin Malo, A., Mallol, J., Castillo, D. et al. Factors affecting beta 2-microglobulin plasma concentration during hemodialysis. Int J Artif Organs 1989, 12: 509-514.

290. DiRaimondo, C.R. \& Pollak, V.E. Beta 2-microglobulin kinetics in maintenance hemodialysis: a comparison of conventional and high-flux dialyzers and the effects of dialyzer reuse. Am J Kidney Dis 1989, 13: 390-395.

291. Goldman, M., Lagmiche, M., Dhaene, M., Amraoui, Z., Thayse, C. \& Vanherweghem, J.L. Adsorption of beta 2-microglobulin on dialysis membranes: comparison of different dialyzers and effects of reuse procedures. Int $J$ Artif Organs 1989, 12: 373-378.

292. Floege, J., Wilks, M., Shaldon, S., Koch, K.M. \& Smeby, L.C. Beta-2 kinetics during hemofiltration. Nephrol Dial Transplant 1988, 3: 784-789.

293. Colombi, A. \& Wegmann, W. Beta-2 microglobulin amyloidosis in a patient on long-term continuous ambulatory peritoneal dialysis (CAPD). Perit Dial Int 1989, 9: $321-34$.

294. Jadoul, M., Malghem, J., Pirson, Y., Maldague, B. \& van Ypersele de Strihou, C. Effect of renal transplantation on the radiological signs of dialysis amyloid osteoarthropathy. Clin Nephrol 1989, 32: 194-197.

295. Cornelis, F., Bardin, T., Faller, B. et al. Rheumatic syndromes and beta 2-microglobulin amyloidosis in patients receiving long-term peritoneal dialysis. Arthritis Rheum 1989, 32: 785-788.

296. Sethi, D., Murphy, C.M., Brown, E.A., Muller, B.R. \& Gower, P.E. Clearance of beta-2-microglobulin using continuous ambulatory peritoneal dialysis. Nephron 1989, 52: $352-355$.

297. Acchiardo, S., Kraus, A.P.J. \& Jennings, B.R. Beta 2microglobulin levels in patients with renal unsufficiency. Am J Kidney Dis 1989, 13: 70-74.

298. Mistry, C.D., O'Donoghue, D.J., Nelson, S., Gokal, R. \& Ballardie, F.W. Kinetic and clinical studies of beta 2microglobulin in continuous ambulatory peritoneal dialysis: influence of renal and enhanced peritoneal clearances using glucose polymer. Nephrol Dial Transplant 1990, 5: 513-519.

299. Shaldon, S., Koch, K.M., Quellhorst, E., Lonnemann, G. \& Dinarello, C.A. CAPD is a second class treatment. Contrib Nephrol 1985, 44: 163-172.

300. Linke, R.P., Hampl, H., Lobeck, H. et al. Lysine-specific cleavage of Beta-2 microglobulin in amyloid deposits associated with haemodialysis. Kidney Int 1990, 36: 675681.

301. Ogawa, H., Saito, A., Oda, O., Nakajima, M. \& Chung, T.G. Detection of a novel beta-2 microglobulin in the serum of hemodialysis patients and its amyloidogenic predisposition. Clin Nephrol 1988, 30: 142-152.

302. Argiles, A., Mourad, G., Atkins, R.C. \& Mion, C.H. New insights into the pathogenesis of haemodialysis-associated amyloidosis. Sem Dial 1990, 3: 149-152.

303. Koch, K.M., Dialysis-related amyloidosis. Kidney Int 1992, 41: $1416-1429$.
304. Zingraff, J. \& Drueke, T. Can the nephrologist prevent dialysis-related amyloidosis? Am J Kidney Dis 1991, 18: $1-11$.

305. Nelson, S.R., Hawkins, P.N., Richardson, S. et al. Imaging of haemodialysis-associated amyloidosis wih ${ }^{123} \mathrm{I}$-serum amyloid P component. Lancet 1991, 338: 335-339.

306. Floege, J,. Burchert, W., Brandis, A. et al. Imaging of dialysis-related amyloid (AB-amyloid) deposits with ${ }^{131} \mathrm{I}$ beta 2-microglobulin. Kidney Int 1990, 38: 1169-1176.

307. Hawkins, P.N., Lavender, J.P., Myers, M.J. \& Pepys, M.B. Diagnostic imaging of amyloid: biological targeting by circulating human serum amyloid $\mathrm{P}$ component. Lancet 1988, 1: $1413-1418$.

308. Takemoto, S., Terasaki, P.I., Cecka, M., Cho, Y.W., Gjertson, D.W. For the UNOS Scientifici Renal Transplant Registry. Survival of nationally shared, HLA-matched kidney transplants from cadaveric donors. $N$ Engl J Med 1992, 327: 834-839.

309. Cecka, J.M., Cho, Y.W. \& Terasaki, P.I. Analysis of the UNOs scientific renal transplant registry at three years early events affecting transplant success. Transplantation 1992, 53(1): 59-64.

310. Opelz, G,. Mytilineos, J. \& Scherer, S. Survival of DNA HLA-DR typed and matched cadaver kidney transplants. Lancet 1991, 338: 461-463.

311. First, M.R. Renal transplantation for the nephrologist: new immunosuppressive drugs. Am J Kidney Dis 1992, 19(1): 3-9.

312. Strom, T.B. Molecular immunology and immunopharmacology of allograft rejection. Kidney Int 1992, 42(S38): 182-187.

313. MacLeod, A.M. \& Thomson, A.W. FK506: an immunosuppressant for the 1990's. Lancet 1991, 337: 25-27.

314. Kahan, B.D., Chang, T.Y. \& Sehgal, S.N. Preclinical evaluation of a new potent immunosuppressive agent, Rapamycin. Transplantation 1991, 52: 185-191.

315. Platz, K.P., Sollinger, H.W,. Hullett, D.A. et al. RS61443 - a new, potent immunosuppressive agent. Transplantation 1991, 51: 27-31.

315. Lai, K.N., Mac-Moune Lai, F. \& Vallance-Owen, J. A short-term controlled trial of cyclosporin A in Is A nephropathy. Transplant Proc 1988, 20 (Suppl 4) 297.

316. Suzuki, S. \& Amemiya, H. 15-Deoxyspergualin - A novel immunosuppressant: experimental studies and clinical trials. Transplant Immunol Lett 1990, 7: 17-19.

317. Kohler, G. \& Milstein, C. Continuous cultures of fused cells secreting antibody of predefined specificity. Nature 1975 , 256: 495-497.

318. Winter, G. \& Milstein, C. Man-made antibodies. Nature 1991, 349: 293-299.

319. Amlot, P.L., Cataigne, T.P. \& Sweny, P. A chimeric CD7 monoclonal antibody (SDZ CHM 380) for organ transplanation. Transplantation and Immunology Letter 1991, 7: 3.

320. Sablinski, T., Hancock, W.W., Tilney, N.L. \& KupiecWeglinski, J.W. CD4 monoclonal antibodies in organ transplantation. A review of progress. Transplantation 1991, 52: 579-589.

321. Tolkoff-Rubin, N., Rothlein, R., Scharschmidt, L. et al. Immunosuppression with anti-ICAM-I (CD54) $\mathrm{mAb}$ in renal allograft recipients (Abstract). J Am Soc Nephrol 1991, 2: 820 .

322. Abramowicz, D., Pradier, O., Marchant, A. et al. Induction of thrombosis within renal grafts by high dose prophylactic OKT3. Lancet 1992, 339(8796): 777-778.

323. Soulillou, J.P., Cantarovich, D., Le Mauff, B. et al. Randomized controlled trial of a monoclonal antibody against the interleukin-2 receptor (33B3.1) as compared with rabbit antithymocyte globulin for prophylaxis against rejection of renal allografts. $N$ Engl J Med 1990, 322: 1175-1182. 
324. Mathew, T.H. Ideal immunosuppression after renal transplantation: are steroids needed? In: Andreucci, V.E. \& Fine, L.G. (eds) International Year Book of Nephrology. Springer Verlag, London, 1992, pp. 299- 312.

325. Sweny, P., Lui, S.F., Scoble, J.E., Varghese, Z., Fernando, O.N. \& Moorhead, J.F. Conversion of stable renal allografts at one year from cyclosporin $A$ to azathioprine: a randomized controlled trial. Transpl Int 1990, 3: 19-22.

326. Thistlewaite, J.R., Gaber, A.O., Haag, B.W. et al. OKT3 treatment of steroid-resistant renal allograft rejection. Transplantation 1987, 43(2): 176-184.
327. Cantarovich, D., Le Mauff, B., Hourmant, M. et al. Anti-interleukin 2 receptor monoclonal antibody in the treatment of ongoing acute rejection episodes of human kidney graft - a pilot study. Transplantation 1989, 47: 454-457.

328. Webb, A.T., Plant, M., Reaveley, D.A. et al. Lipid and lipoprotein (a) concentrations in renal transplant patients. Nephrol Dial Transplant 1992, 7: 636-641.

329. Proceedings of the 4th Alexis Carrel Conference. Sweden 1992. Transplant Proceedings 1993, Vol. 25. No. 2. 